\title{
Learning and the Value of Trade Relationships
}

Monarch, Ryan and Tim Schmidt-Eisenlohr

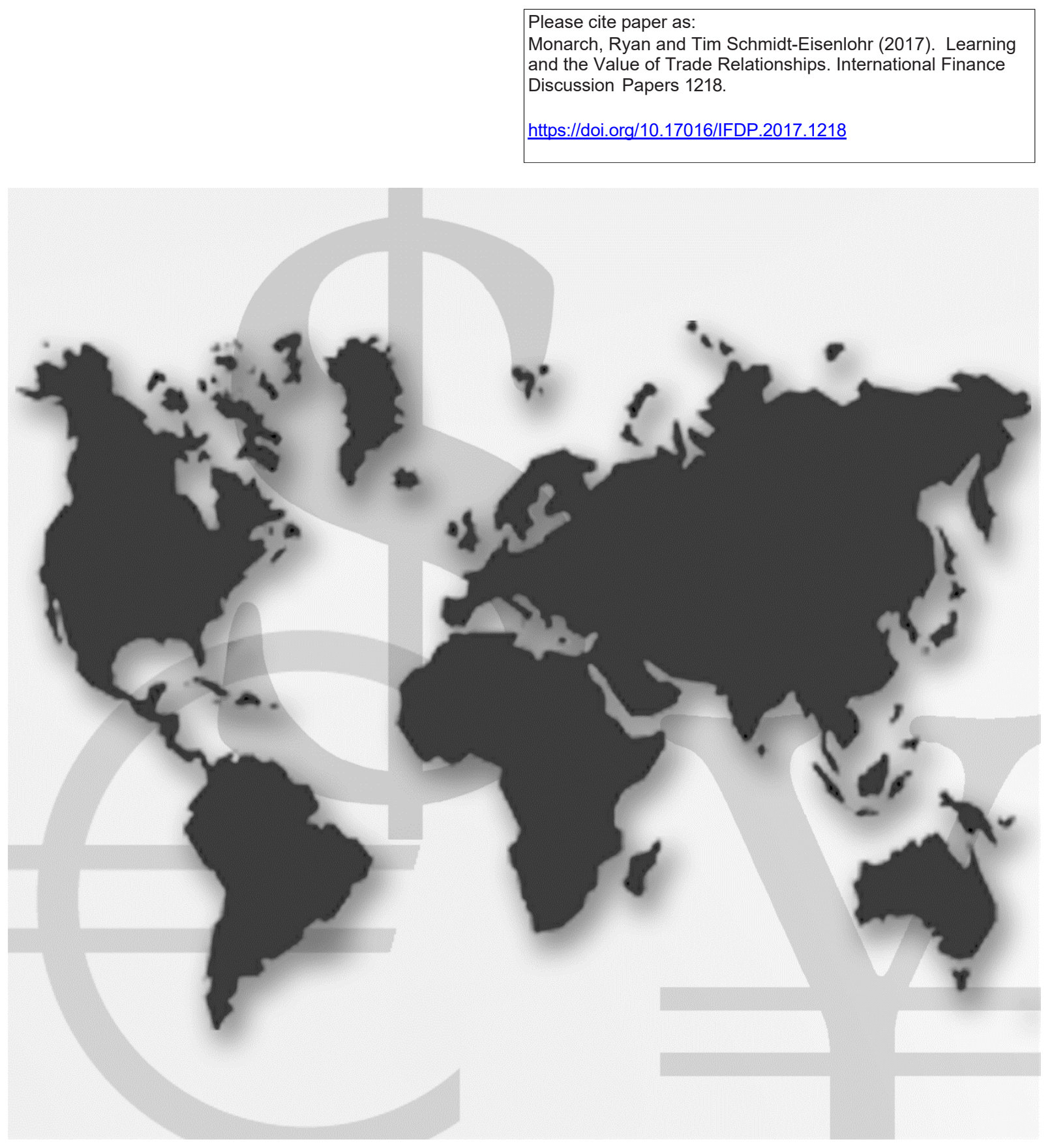

\section{International Finance Discussion Papers}

Board of Governors of the Federal Reserve System

Number 1218

November 2017 


\title{
Board of Governors of the Federal Reserve System \\ International Finance Discussion Papers
}

Number 1218

November 2017

\section{Learning and the Value of Trade Relationships}

\author{
Ryan Monarch \\ Tim Schmidt-Eisenlohr
}

NOTE: International Finance Discussion Papers are preliminary materials circulated to stimulate discussion and critical comment. References to International Finance Discussion Papers (other than an acknowledgment that the writer has had access to unpublished material) should be cleared with the author or authors. Recent IFDPs are available on the Web at www.federalreserve.gov/pubs/ifdp/. This paper can be downloaded without charge from the Social Science Research Network electronic library at www.ssrn.com. 


\title{
Learning and the Value of Trade Relationships
}

\author{
Ryan Monarch* \\ Tim Schmidt-Eisenlohr*
}

This paper quantifies the value of importer-exporter relationships. We show that almost 80 percent of U.S. imports take place in pre-existing relationships, with sizable heterogeneity across countries, and show that traded quantities and survival increase as relationships age. We develop a two-country general equilibrium trade model with learning that is consistent with these facts. A model-based measure of relationship value explains survival during the 2008-09 crisis. Knowledge accumulated within long-term relationships is quantitatively important: wiping out all memory from previous interactions, on average, reduces consumption by 5 percent on impact and by 48 percent over the transition back to steady state.

Keywords: International Trade, Firm Relationships, Learning, Trade Dynamics

\section{JEL classifications: F11,F14,L14,D22}

The authors are staff economists in the Division of International Finance, Board of Governors of the Federal Reserve System, Washington, D.C. 20551 U.S.A. The views in this paper are solely the responsibility of the author(s) and should not be interpreted as reflecting the views of the Board of Governors of the Federal Reserve System or of any other person associated with the Federal Reserve System. Contact: ryan.p.monarch@frb.gov, t.schmidteisenlohr@gmail.com

*We thank Bernardo Blum, Fabrice Defever, Brian Kovak, Florian Mayneris, Andreas Moxnes, Ameet Morjaria, Emanuel Ornelas, James Rauch, Peter Schott, and Olga Timoshenko for helpful discussions, as well as seminar participants at the Federal Reserve Board, the World Bank, the Rocky Mountain Empirical Trade conference, the Society for Economic Dynamics conference, the Washington Area International Trade Symposium, the European Bank for Reconstruction and Development, Nottingham University, Stockholm University, Uppsala University, UQAM, University of Montreal, Carnegie Mellon University, University of Maryland, University of Virginia, the Southern Economic Association meetings, the Stanford RDC Conference, the European Trade Study Group, the Federal Reserve Board International Trade Conference, and the Empirical Investigations in International Trade conference for helpful comments. This work was undertaken while Monarch and Schmidt-Eisenlohr were under Special Sworn Status at the U.S. Census Bureau. Any opinions and conclusions expressed herein are those of the authors and do not necessarily represent the views of the U.S. Census Bureau, the Federal Reserve Board, or anyone affiliated with the Federal Reserve System. All results have been reviewed to ensure no confidential information is disclosed. 


\section{Introduction}

Successful firm-to-firm relationships are central to modern production, as intermediate inputs often pass from one firm to another. Economists have long argued that interactions between firms are not frictionless (for example, Coase (1937) and Grossman and Hart (1986)). That said, excepting theories of how multinational firms source and organize production (such as Antràs (2003) and Antràs and Helpman (2004)), theoretical models in macroeconomics and international trade typically abstract from transactional frictions. Recent work by Macchiavello and Morjaria (2015) has shed new light on those frictions, providing microeconomic evidence on the value of relationships in Kenyan rose exports. Building on Araujo et al. (2012), they show that relational contracts and learning are central to firms' production decisions and responses to shocks 1

Exploiting U.S. census data, this paper extends this line of research in two distinct ways. First, it documents the importance of continuing relationships in data that cover the universe of transactions between U.S. importers and their foreign suppliers: 80 percent of trade occurs in established relationships. Second, it embeds a model of relational contracting and learning into a general equilibrium trade model. Calibrating the model to the data and solving for the dynamic evolution of trade patterns, we quantify the value of relationships by estimating the welfare effects of "relationship shocks". We find immediate welfare losses of, on average, 5 percent of annual consumption from wiping out all relationship-specific knowledge, with total losses averaging 48 percent of annual consumption.

We start by establishing several facts. First, long-term relationships are central, with almost half of U.S. imports in importer-exporter relationships that are three years old or older.2 Second, the importance of relationships differs substantially

\footnotetext{
${ }^{1}$ In related work, Antràs and Foley (2015) reveal that learning also plays a key role for the dynamics of payment terms in international trade.

${ }^{2}$ This statistic refers only to arm's-length importer-exporter relationships. Including relatedparty trade would increase this fraction.
} 
by country, with $62 \%$ of U.S.-Japan trade in relationships that are over three years old, for example, compared with $33 \%$ of U.S.-Spain trade. These differences are not driven by sectoral specialization at the country level. Third, the amount traded within a relationship rises as it ages, a result that is robust to accommodating "partial year effects" $3^{3}$ Fourth, the probability a relationship survives increases as it ages. Finally, we find that source countries with better institutions tend to have longer relationships.

Motivated by these findings, we set up a dynamic two-country general equilibrium trade model where importers learn about the quality of their foreign suppliers over time. An importer believes they will receive a usable product from a new supplier with some country-specific probability. With each successful interaction, the importer's belief about the supplier's suitability improves, leading to an increase in the quantity traded and a greater probability of survival. We quantify the value of a relationship as the expected future stream of profits from that relationship, a term that varies both by supplier country and with relationship age.

The model is calibrated to U.S. relationship-level import data. We estimate separate parameters for each of the top 10 trading partners of the United States, using moments from each country's distributions of relationships and trade across age cohorts. The parsimonious model generates age distributions that closely match those in the data. Furthermore, the probability that a relationship survived the crisis of 2008 to 2009 is strongly correlated with our measure of relationship value, even when accounting for the age of the relationship, country fixed effects, and other covariates. Based on the calibration, long-term relationships are, on average, 21.2 times more valuable than new relationships, with a maximum of 79 (France) and a minimum of 5.1 (China).

\footnotetext{
3 "Partial year effects", a term coined by Bernard et al. (2017), refers to the differences in growth rates for firms that begin trading in January of a year compared to those that begin in December. We address this concern by showing that our result on trade growth within relationships also holds when only looking at relationships that started trading in the first quarter of a year.
} 
We then solve the two-country general equilibrium trade model numerically and quantify how disruptions to relationships affect welfare. Our first experiment studies the effects of a "reset" of all relationships, meaning that all established relationships are wiped out and replaced with the same number of new relationships. Output declines sharply and only slowly moves back to steady-state levels, taking several years. The effect of the shock differs across countries: as one example, resetting all relationships is more costly for Germany than for the United Kingdom because, in Germany, long-term relationships have higher survival probabilities and therefore contribute more to overall trade. Across all countries in our model, the total consumption loss in the transition back to a steady state averages 48 percent of the annual steady-state value of consumption, with an initial loss on impact of 5 percent. In a related experiment, we show the effects of simply wiping out all existing relationships without replacement, meaning that the economy not only loses the knowledge accumulated in old relationships, but also has to bear the additional costs of recreating all relationships. Initial losses are larger in this scenario because more resources are diverted to cover entry costs. The dynamic path back to steady state, however, looks very similar, as the learning structure is unchanged. To sum up, relationships represent a type of capital for firms, and disruptions to those relationships translate into worse performance for firms and lower welfare for consumers for multiple years.

There is a burgeoning literature that, like our paper, uses "two sided" international trade data to study relationships. Blum et al. (2013) use linked data on importers and exporters in Latin American, showing that firms that export only occasionally often export the same goods to the same importers. Eaton et al. (2014) study relationships between Colombian exporters and U.S. importers. They calibrate a search and matching model with learning to match exporter decisions, including sales, number of clients, and transition probabilities. Kamal and Sundaram (2016) use the same data to determine how likely Bangladeshi textile producers are to follow other exporters in the same city in exporting to a particular 
partner. Monarch (2014) applies a dynamic discrete choice model to the sourcing decisions of U.S. importers over time to estimate the cost of switching suppliers. Two-sided trade data are also used to study the effects of firm heterogeneity on trade: Bernard et al. (forthcoming) use Norwegian trade data to develop a model of relationship-specific fixed costs of exporting. $!^{4}$ Carballo et al. (2013) look at relationships in several Latin American countries and develop a model to analyze the role of competition. Heise (2015) studies the effects of firm-to-firm relationships on price rigidity and exchange-rate pass-through using U.S. importer data and finds that prices grow within a relationship as trade increases. We complement this literature by focusing on cross-country heterogeneity in relationship patterns and using it to quantify the value of relationships.

A set of papers directly study the role of long-term relationships for international trade with more disaggregated data..$^{5}$ Egan and Mody (1992) provide survey evidence that importers from developed countries initiate emerging-economy trade relationships with very small purchases. Rauch and Watson (2003) rationalize this finding in a model with importer learning. In their model, relationship persistence is the result of a dynamic trade-off between the per-period costs of a supplier and the reliability of other potential partners. Macchiavello and Morjaria (2015) study Kenyan rose exporters and find that the value of a relationship increases with age. They also show that in long-run relationships, buyers have already learned the type of the seller, and, therefore, no costly signaling is necessary in times of crisis. Heise et al. (2015) study how changes in trade policy may affect the organization of supply chains. Our results on the resilience of long-term relationships during the 2008-09 crisis also relate to work by Carballo (2016), who shows that firm exit

\footnotetext{
${ }^{4}$ Benguria (2015) also studies two-sided heterogeneity, using data from Colombia.

${ }^{5}$ Earlier work on buyer-supplier relationships in international trade centered on the study of networks. Rauch (2001) surveys the potential for transnational cultural networks to reduce barriers to entry, and Rauch and Watson (2004) present a model where economic agents use their networks to produce or export more efficiently or to become an intermediary. Krautheim (2012) models how information sharing in networks may affect the fixed costs of exporting and thereby the measured effects of distance on trade. Chaney (2014) studies a dynamic model where firms search for additional trade opportunities through their networks.
} 
during the Great Trade Collapse was lower for integrated firms.

Our model directly builds on Araujo et al. (2016), who study learning by exporters and test reduced-form predictions with Belgian firm-level data..$^{6}$ In the tradition of the seminal work of Jovanovic (1982), a number of other papers consider firm learning in different contexts, such as its relationship with exports (Albornoz et al. (2012)), foreign demand (Ruhl and Willis (2017)), growth Arkolakis et al. (forthcoming) $)$, and international prices (Bastos et al. (2015)).

Finally, our work adds to the wider literature on trade dynamics. Alvarez and Lucas (2007) develop a dynamic solution to the general equilibrium trade model of Eaton and Kortum (2002), while Eaton et al. (2016) embed this framework in an international real business cycle model. Several papers study how firm behavior shapes aggregate trade dynamics. Ruhl (2008) examines the extensive margin of trade and its implications for trade elasticities. Atkeson and Burstein (2010) model the dynamic product and process innovation decision of exporters. Alessandria and Choi (2014) show that long-term gains of tariff cuts are larger when not only sunk costs of exporting, but also continuation costs, are taken into account. Alessandria et al. (2014) consider the sluggish response of trade volumes to changes in trade barriers or price shifts by modeling the buildup of a firm's exporting capacity over time.

In sum, our paper contributes to the literature in two ways. First, it documents the importance of long-term relationships across countries using the universe of U.S. import data. Second, it embeds a model of relational contracts and learning into a dynamic general equilibrium model, and, after calibrating it to the data and

\footnotetext{
${ }^{6}$ Our work is also related to the wider literature on learning and entry. Impullitti et al. (2013) develop a model of entry and exit where firms pay sunk costs to start exporting and face persistent productivity shocks. Besedeš and Prusa (2006) study the effect of product differentiation on U.S. importer relationships with their suppliers. Besedeš (2008) finds that reliable suppliers lead to longer relationships and larger export orders, while only a small fraction of relationships end as a result of switching behavior. Timoshenko (2015a) looks at Colombian firm-level data to distinguish between the role of sunk costs and learning for the persistence of exporting. Timoshenko (2015b) finds that new exporters do more product switching, and develops a model of learning that rationalizes this finding.
} 
solving for the dynamic transition path of the economy, provides a quantitative evaluation of the value of relationships.

The rest of the paper is organized as follows. Section 2 describes the importerexporter data and presents empirical findings on trade relationships. Section 3 discusses the model of supplier learning and how it fits into a general equilibrium framework. Section 4 describes the calibration exercise and the quantitative evaluations. Section 5 concludes.

\section{Empirics}

\subsection{Data definitions and cleaning}

The data come from the Longitudinal Foreign Trade and Transaction Database (LFTTD), which is collected by U.S. Customs and Border Protection and maintained by the U.S. Census Bureau. Every transaction in which a U.S. company imports or exports a product requires the filing of Form 7501 with U.S. Customs and Border Protection, and the LFTTD contains the information from these forms $]^{7}$ There are typically close to 50 million transactions per year. In this paper, we utilize the import data, which include quantity and value exchanged for each transaction, Harmonized System (HS) 10 product classification, date of import and export, port information, country of origin, and a code identifying the foreign exporting partner. Known as the manufacturing ID, or MID, the foreign partner identifier contains limited information on the name, address, and city of the foreign supplier 8 Kamal and Monarch (forthcoming) find substantial support for the use of the MID as a reliable, unique identifier, both over time and in cross-section. Pierce and Schott (2012), Monarch (2014), Kamal and Sundaram (2016), Eaton et

\begin{tabular}{l}
\hline${ }^{7}$ Approximately 80 to 85 percent of these customs forms are filled out electronically (Krizan \\
\hline$(2012))$. \\
\hline${ }^{8}$ Specifically, the MID contains the first three letters of the producer's city, six characters from \\
the producer's name, up to four numeric characters from its address, and the ISO2 code for the \\
country of origin.
\end{tabular}


al. (2014), and Heise (2015) have all used this variable in the context of studying U.S. firm relationships in international trade.

For our analysis, we eliminate related-party transactions, as U.S. firms who are importing from foreign affiliates will likely have very different relationship dynamics than those involved in arm's-length transactions. U.S. importers whose domestic operations are classified as wholesale or retail are also dropped. We follow the methods of Bernard et al. (2009) for cleaning the LFTTD. Specifically, we drop all transactions with imputed quantities or values (which are typically very low-value transactions) or converted quantities or values. All of our results come from the U.S. import data on relationships from 1997 through 2011.

Finally, some definitions: an importer is a U.S. importing firm, while an exporter is a non-U.S. firm identified by the MID as exporting to the United States. A relationship is an observation of an importer-exporter combination. The age of a relationship is how many consecutive years that relationship has appeared in the U.S. import data, with the first observation of a relationship considered to be age 0.9 We call the distribution of relationship counts over different ages the count distribution, and the distribution of trade values across relationships of different ages the value distribution.

\subsection{Empirical Findings}

Most trade is in long-term relationships. Table 1 presents a breakdown of U.S. arm's-length imports in 2011 by the age of relationships. Two points stand out. First, the largest fraction of trade (47\%) occurs in long-term relationshipsthose of three or more years- while new relationships account for only about onefifth of U.S. imports 10 Second, new relationships account for the vast majority of

\footnotetext{
${ }^{9}$ The distinction between consecutive and non-consecutive years of a relationship makes little difference to any of the findings below. Results using non-consecutive years of a relationship are available upon request.

${ }^{10} \mathrm{~A}$ one-year-old relationship is one that has appeared in two consecutive years of data.
} 
total relationships in 2011.

The complete distributions for 2011 are shown in Figure 1; both the count distribution and the value distribution decrease nearly monotonically with age 11 In line with Table 1, the value distribution is much more skewed toward higher ages.

These facts mask substantial heterogeneity in the age structure of trade at the source-country level. Table 2 presents a summary of the count distributions and value distributions for the top 20 trading partners of the United States. There is a wide range for the share of long-term trade across countries: 33 percent of U.S. arm's-length imports from Spain occur in long-term relationships, but 67 percent of imports from Taiwan do. Taiwan also has roughly double the share of longterm relationships as Spain. There is a positive correlation between the share of long-term relationships and the share of trade in long-term relationships, shown in Figure 2.

If these differences in the age structure of trade were the result of product specialization across source countries, the interpretation of the above findings would be quite different. To investigate this possibility, we conduct two exercises.

First, we check whether countries with more trade in old relationships in the aggregate also have more trade in old relationships at the sectoral level. More specifically, we calculate each country's share of trade in older relationships in the aggregate (as in Table 2), as well as for textiles (HS2 50-63), machinery and electrical goods (HS2 84-85), and footwear/headgear (HS2 64-67). We then calculate rank correlations to see if the country orderings within industries are similar to the aggregate country ordering. Results are presented in Table 3: the correlations are all positive, implying that aggregate and sector-level patterns are similar.

Second, we run regressions that confirm specialization across sectors does not

\footnotetext{
${ }^{11}$ Any relationship 11 years or older is classified as 11 years old. The uptick in traded value for relationships for the final segment is explained by this simplification; extending the maximum age of a relationship forward more years smoothes the tail of the distribution.
} 
drive the age composition of relationships across countries. We regress the countrysector share of trade in an relationship on country fixed effects. We then add sector fixed effects to the regression. The country fixed effects obtained from these two regressions are extremely similar - with a correlation of 0.98 (0.94) when looking at the number of (value of trade in) old relationships.

These two exercises imply that the heterogeneous trade shares of relationships across countries are not driven by the sectoral composition of exports.

Trade increases as relationships age. The differences between the count distributions and the value distributions imply that, on average, older relationships trade more. One explanation for this finding is that the amount traded within a surviving relationship increases over time.

To track trade within relationships, we generate cohorts of newly formed relationships for each year from 1998 to 2006 and follow them over time ${ }^{12}$ Table 4 presents the results of the following regression with relationship fixed effects:

$$
\text { Value }_{m x, t}=\sum_{k=1}^{K} \beta_{k} \mathbb{1}\left[\text { Age }_{m x, t}=k\right]+f_{m x}+u_{m x, t}
$$

where Value is the log value of trade between a U.S. importer $m$ and an exporter $x$ at time $t$, Age is the age of that relationship at time $t$ (with $A g e_{0}$ - the first year a relationship is found- is omitted), and $f_{m x}$ is a relationship fixed effect. The regression is run separately for relationships that last a total of $K=5,7,10$, and 13 years.

As can be seen from the left panel of Table 4, as a relationship ages, the amount traded increases. As a relationship moves closer to its end, trade falls off, but for all relationships, trade initially grows over multiple years.13 Importantly, this result

\footnotetext{
${ }^{12}$ A new relationship in 1998 is one not found in 1997, our first year of data. The most recent year of data is 2011 .

${ }^{13}$ Heise (2015) performs a similar exercise, also using the LFTTD data. He builds a model with productivity shocks that can account for the fall-off in trade toward the end of a relationship.
} 
is robust to accounting for "partial year effects" - recent work by Bernard et al. (2017) has shown firms that start exporting in January trade much more in a year than firms that start exporting in December. To correctly calculate trade growth for the first year, one needs to account for this pattern. As can be seen in Columns (5)-(8) of Table 4, even when looking only at relationships that began in January, February or March (where partial-year effects should be minimal), trade increases in relationship age 14 The results are presented graphically in Figure 3 by graphing the $\beta_{k}$ terms for $K=5,7,10$, and 13-year relationships, where Panel A shows the entire sample of relationships, and Panel B plots only those relationships that started exporting in the first quarter of the year.

The survival probability increases as relationships age. We next explore the survival probability of a trading relationship. Figure 4 shows the conditional survival probability of a relationship by age: what share of relationships of age $k$ in 2010 survive into 2011? The figure shows that the older a relationship is, the higher the likelihood that relationship survives an additional year.

A proportional hazard model of relationship survival that accounts for the effects of importer size, exporter size, and source country institutional quality allows greater precision for calculating survival probabilities. Following cohorts of new relationships, we define the hazard as the disappearance of a relationship. Echoing the picture in Figure 4, Figure 5 shows that there is little decline in survival- the probability a relationship survives at least to age $k$-after age 4 . This finding is not driven by firm-level entry and exit. When estimating the probability of relationship survival on the sample of firms existing for 3 years or 7 years (approximating a balanced panel of firms) we find qualitatively similar results for the survival model. Because we also control for total importer and exporter While, in principle, it should be possible to add his mechanism to our model, this addition would raise substantial computational challenges.

${ }^{14}$ We will also account for these effects when we estimate our model. 
firm size, firm-level trends are not driving these findings 15 Nor is it the case that relationships with larger initial trade volumes are driving these results; including first-year relationship size in the hazard model specification does not alter the finding that the probability of survival is lowest for the youngest relationships.

\section{Source countries with better institutions have longer relationships. Hav-} ing shown the importance of long-term relationships in international trade, we now consider the determinants of relationship ages across countries through reducedform regressions that control for firm and product characteristics.

Our specification is as follows:

$$
\text { RelLength }_{m x}=\beta_{m} Y_{m}+\beta_{x} Y_{x}+\beta_{c} Y_{c}+f_{i}+u_{m x}
$$

where RelLength is the age of a relationship in 2011 between U.S. importer $m$ and exporter $x . Y_{m}$ and $Y_{x}$ are sets of importer or exporter controls, which include the following variables for importers and exporters: firm age (where firm "birth" is proxied by the first year of appearing in U.S. import data), firm size (proxied by total imports), number of relationships, and number of products traded. Regressions also include importer-industry fixed effects $f_{i}{ }^{16} Y_{c}$ is a set of country controls that includes rule of law, per capita GDP, distance from the United States, a trade agreement dummy, and an OECD membership dummy

Columns (1) to (5) of Table 5 present the results. The regressions show that U.S. importers have longer relationships with exporters from countries with better institutions (higher rule of law) 18 Interestingly, despite its general importance for trade levels and patterns, distance is uncorrelated with relationship length.

\footnotetext{
${ }^{15}$ We proxy importer size by total imports and exporter size by total exports to the United States.

${ }^{16}$ Because importers can import from more than one industry, we assign each importer the HS2 industry that it imports the most from.

${ }^{17}$ The rule of law variable comes from Kaufmann et al. (2010).

${ }^{18}$ These results are robust to restricting the sample to only machinery and electric technological products (HS 84-86) or to textile products (HS 50-63).
} 
Similarly, Free Trade Agreements do not seem to affect the age of relationships. In contrast, source countries with higher GDP per capita tend to have longer relationships- an effect that disappears when including the OECD dummy.

To sum up, in this section we show that long-term relationships are a meaningful component of international trade: almost half of U.S. imports occur within older relationships. Distributions for individual source countries vary greatly. Second, as a relationship ages, trade increases and the relationship itself becomes more likely to survive an additional year. Third, long-term relationships are more likely to arise in countries with good institutions or higher per-capita GDP. Guided by these facts, we develop a model of relationships and learning, calibrate its parameters country by country, and analyze the value of relationships.

\section{Model}

This section outlines a model of learning in trade relationships, applying the model of exporter learning about foreign demand from Araujo et al. (2016) to the context of U.S. importers learning about individual foreign suppliers.

\subsection{Basic Setup and Learning}

An exporter encounters an opportunity to transact with an importer. The importer has a particular design specification they require for producing their final good but is unsure whether the supplier can produce according to their specification. The importer has to pay the buyer before they can evaluate the suitability of the product 19

In each country, some fraction $\widehat{\theta}$ of managers are effective (meaning they ensure

\footnotetext{
${ }^{19}$ That is, the buyer has to fully pay before delivery - cash-in-advance payment. Or, the buyer may pay after delivery but without having sufficient time to verify the quality of the product before paying. We show in appendix $\mathrm{D}$ how this assumption can be relaxed.
} 
production occurs according to the importer's specification), whereas the remainder are not. However, even if a manager is ineffective, the underlying quality of the firm (including the education of its workers, its experience in production, etc.) may ensure that a particular shipment is usable. This event occurs with probability $\lambda$.

Each period, following the interaction, the buyer must decide whether to continue transacting with the seller. A relationship will only be continued if the prior shipment was usable. Relationships can also dissolve for exogenous reasons with probability $\delta \in(0,1)$. Finally, the maximum age a relationship can last is $K$.

Bayesian updating As there are two types of suppliers in the economy, learning plays a central role. Initially, buyers believe (correctly) that the probability the supplier's manager is effective is equal to the population mean, $\widehat{\theta}$. Every period that a relationship survives, buyers update their beliefs according to Bayes' rule. If a buyer has successfully purchased from a supplier for $k$ periods, the posterior probability that the manager is effective can be derived as:

$$
\theta_{k}=\frac{\widehat{\theta}}{\widehat{\theta}+(1-\hat{\theta}) \lambda^{k}}
$$

Importantly, the probability only changes with the length of time that a buyer has been buying from the same supplier. It is easy to see that for large $k, \theta_{k}$ converges to 1 ; that is, the buyer is almost certain that the manager is effective.

The delivery probability Consider again a relationship of age $k$. The buyer will receive the goods from the supplier next period under two scenarios: either the manager is effective (an event with expected probability $\theta_{k}$ ), or the manager is not effective, but the supplier delivers a suitable product anyway (an event with expected probability $\left.\left(1-\theta_{k}\right) \lambda\right)$. Thus, after $k$ successful transactions, the delivery 
probability is:

$$
\tilde{\theta}_{k}=\left(\theta_{k}+\left(1-\theta_{k}\right) \lambda\right)=\left(\frac{\widehat{\theta}}{\widehat{\theta}+(1-\widehat{\theta}) \lambda^{k}}\right)(1-\lambda)+\lambda .
$$

The delivery probability is a key object in the model. It is increasing in $k$, the age of the relationship, as well as in $\hat{\theta}$, the fraction of effective managers in the source country 20

There are two competing effects of the parameter $\lambda$ on the delivery probability. Countries that have better firms (a higher $\lambda$ ) have a higher initial delivery probability $\tilde{\theta}_{0}$, but slower learning, meaning smaller increases in the delivery probability over time. ${ }^{21}$ The differences can be seen in Figure 6, which illustrates the delivery probability for both high and low $\lambda$. For young relationships, the direct effect of $\lambda$ dominates, and the delivery probability is higher for higher $\lambda$. For older relationships, the negative effect on $\tilde{\theta}_{k}$ from slower learning is more important, generating a delivery probability that is lower for higher $\lambda$.

Relationship survival A relationship of age $k$ survives for another period if it is not hit by the exogenous dissolution shock and if there is a successful delivery. It therefore survives with (conditional) probability: $\operatorname{surv}_{k}=(1-\delta) \tilde{\theta}_{k}$. Using this expression and Equation (4), it is straightforward to see that, matching our empirical finding, as a relationship ages $(k \uparrow)$, the conditional probability of survival increases, converging to $1-\delta$.

The probability that a relationship is still alive after $k$ periods, alive ${ }_{k}$, can be defined recursively: it is the probability a relationship is still alive after $k-1$ periods times the probability of surviving from age $k-1$ to $k$ : alive $_{k}=$ alive $_{k-1}$ surv $_{k-1}$. Because the probability a relationship is alive at least 0 periods is 1 (that is,

$$
\begin{aligned}
& { }^{20} \frac{\partial}{\partial \hat{\theta}}\left(\frac{\widehat{\theta}}{\widehat{\theta}+(1-\hat{\theta}) \lambda^{k}}\right)=\frac{\lambda^{k}}{(-\hat{\theta} \lambda+\hat{\theta}+\lambda)^{2}}>0 . \\
& { }^{21} \tilde{\theta}_{0}=\hat{\theta}+(1-\hat{\theta}) \lambda .
\end{aligned}
$$


alive $_{0}=1$ ), we have:

$$
\operatorname{alive}_{k}=(1-\delta)^{k}\left(\lambda^{k}(1-\hat{\theta})+\hat{\theta}\right)
$$

\subsection{The Trade Model}

We consider a Krugman (1980) two-country trade model with dynamics occurring through the evolution of beliefs described previously. Demand for the final good of a monopolistic-competitive supplier has a constant elasticity of substitution $\sigma$. There is also a fixed cost of production $f_{E}$, marginal cost $c$, and an iceberg trade $\operatorname{cost} \tau$. Let $p^{i i}$ refer to the domestic price in countries $i=1,2$ and $p^{i j}$ refer to the price paid in country $j$ for a good from country $i$. We add a superscript $i$ to the probability a quality input is delivered by a particular age group $k$ in country $i$, $\tilde{\theta}_{k}^{i}$. Assume that for domestic sales, there are no iceberg costs (that is, $\tau=1$ ) and there is no problem in delivering the right quality ${ }^{22}$

Firm profits Consider the profits of a firm in country $i$ at time $t$ of age $k$ :

$$
\pi_{t, k}^{i}=p_{t, k}^{i i} q_{t, k}^{i i}+\tilde{\theta}_{k}^{i} p_{t, k}^{i j} q_{t, k}^{i j}-q_{t, k}^{i i} c^{i} w_{t}^{i}-\tau q_{t, k}^{i j} c^{i} w_{t}^{i}-f_{E},
$$

We assume standard CES preferences, implying firm-level demand of $q_{t, k}^{i i}=A_{t}^{i}\left(p_{k}^{i i}\right)^{-\sigma}$ and $q_{t, k}^{i j}=A_{t}^{j}\left(p_{k}^{i j}\right)^{-\sigma} 23$ The first-order conditions of profit maximization imply:

$$
\begin{aligned}
p_{t, k}^{i i}=p_{t}^{i i} & =\frac{\sigma}{\sigma-1} c^{i} w_{t}^{i} \\
p_{t, k}^{i j} & =\frac{\tau}{\tilde{\theta}_{k}^{i}} p_{t}^{i i}
\end{aligned}
$$

\footnotetext{
${ }^{22}$ Of course, even for domestic deliveries, there may be a quality problem. The key assumption here is that the problem is larger for international trade, for example, because communication and travel costs are much higher. For tractability, we focus on the case of no domestic friction, but it would be straightforward to relax that assumption.

${ }^{23}$ Such demand comes from maximizing a CES utility function of the form $Q=$ $\left(\int q(z)^{\frac{\sigma-1}{\sigma}} d z\right)^{\frac{\sigma}{\sigma-1}}$, with the ideal price index $P=\left(\int p(z)^{1-\sigma} d z\right)^{\frac{1}{1-\sigma}}$. In this context, aggregate demand $A=P^{\sigma} Q$.
} 
Profits are hence:

$$
\pi_{t, k}^{i}=\frac{1}{\sigma}\left(p_{t}^{i i}\right)^{1-\sigma}\left(A_{t}^{i}+\tau^{1-\sigma}\left(\tilde{\theta}_{k}^{i}\right)^{\sigma} A_{t}^{j}\right)-f_{E}
$$

With expected (operating) profits from exporting:

$$
\begin{aligned}
\pi_{t, k}^{i j} & =\tilde{\theta}_{k}^{i} p_{t, k}^{i j} q_{t, k}^{i j}-\tau q_{t, k}^{i j} c^{i} w_{t}^{i} \\
& =\frac{\tilde{\theta}_{k}^{i}}{\sigma}\left(p_{t, k}^{i j}\right)^{1-\sigma} A_{t}^{j}=\frac{\tilde{\theta}_{k}^{i}}{\sigma}\left(\frac{\tau}{\tilde{\theta}_{k}^{i}} p_{t}^{i i}\right)^{1-\sigma} A_{t}^{j}
\end{aligned}
$$

The delivery probability, $\tilde{\theta}_{k}^{i}$, affects expected profits from exporting via two channels. First, there is a direct effect, as a sale is more likely to succeed. Second, there is an indirect effect. A higher success probability leads to a larger order and, hence, larger revenues and profits if the trade is successful, as the optimal price $p_{t, k}^{i j}$ decreases in $\tilde{\theta}_{k}^{i}$. A successful international transaction generates revenues of:

$$
R_{t, k}^{i j}=p_{t, k}^{i j} q_{t, k}^{i j}=A_{t}^{j}\left(\frac{\tau \sigma c^{i} w_{t}^{i}}{(\sigma-1) \tilde{\theta}_{k}^{i}}\right)^{1-\sigma}
$$

We can now derive the following proposition that matches our empirical finding:

Proposition 1 Suppose $\lambda<1$. Then, the amount being traded, $R_{t, k}^{i j}$, within a relationship increases with the relationship's age, $k$.

Proof.

$$
\frac{\partial}{\partial k} R_{t, k}^{i j}=A_{t}^{j}\left(\frac{\tau \sigma c^{i} w_{t}^{i}}{\sigma-1}\right)^{1-\sigma}(\sigma-1)\left(\tilde{\theta}_{k}^{i}\right)^{\sigma-2} \frac{\partial}{\partial k} \tilde{\theta}_{k}^{i}>0
$$

as $\tilde{\theta}_{k}=\left(\frac{\widehat{\theta}}{\widehat{\theta}+(1-\widehat{\theta}) \lambda^{k}}\right)(1-\lambda)+\lambda$, and this expression is increasing in $k$ for $\lambda<1$. 


\subsection{Count and Value Distributions}

We can now derive model analogues to the count and value distributions that we studied in Section 2.2. In this section, we drop the $t$ subscript, as we focus on the steady-state distributions ${ }^{24}$ In a steady state, the number of relationships is constant. Let ageshare $_{k}$ denote the fraction of relationships that survived for $k$ periods. Then:

$$
\text { ageshare }_{k}=\text { alive }_{k} / \sum_{s=0}^{K} \text { alive }_{s}=\frac{\text { alive }_{k}}{\sum_{s=0}^{\infty} \text { alive }_{s}-\sum_{s=K}^{\infty} \text { alive }_{s}}
$$

We can directly compare this object to the relationship age shares reported in Section 2.2. Next, we derive the elements of the value distribution. That is, we weigh the number of relationships in a cohort with trade per relationship:

$$
\text { tradeshare }_{k}=\left(R_{t, k}^{i j} \text { alive }_{k}\right) / \sum_{s=0}^{K}\left(R_{t, s}^{i j} \text { alive }_{s}\right) .
$$

Plugging in the expression for revenues (11), we obtain

$$
\text { tradeshare }_{k}=\frac{\left(\tilde{\theta}_{k}^{i}\right)^{\sigma-1} \text { alive }_{k}}{\sum_{s=0}^{K}\left(\tilde{\theta}_{s}^{i}\right)^{\sigma-1} \text { alive }_{s}} .
$$

\footnotetext{
${ }^{24}$ We reintroduce the time dimension below when solving for the dynamic transition path in general equilibrium.
} 


\subsection{The Value of a Relationship}

Define the value of a relationship as the expected sum of future profits. Then the value of a new relationship is:

$$
\begin{aligned}
V_{0}=\mathrm{E}\left[\Pi_{0}\right] & =\sum_{s=0}^{K} \text { alive }_{s} \mathrm{E}\left[\pi_{s}^{i j}\right] \\
& =\frac{1}{\sigma}\left(\tau p^{i i}\right)^{1-\sigma} A^{j} \sum_{s=0}^{K}(1-\delta)^{s}\left(\lambda^{s}(1-\hat{\theta})+\hat{\theta}\right)\left(\tilde{\theta}_{s}^{i}\right)^{\sigma} .
\end{aligned}
$$

Here, an importer is matched with a random supplier at $s=0$ that delivers a quality input with probability $\tilde{\theta}_{0}^{i}$. The importer then slowly learns the type of the supplier over time. Similarly, the sum of expected future profits of a relationship of age $k$ are:

$$
\begin{gathered}
V_{k}=\mathrm{E}\left[\Pi_{k}\right]=\sum_{s=0}^{K-k}\left(\frac{\text { alive }_{k+s}}{\text { alive }_{k}}\right) \mathrm{E}\left[\pi_{k+s}^{i j}\right] \\
=\frac{1}{\sigma}\left(\tau p^{i i}\right)^{1-\sigma} A^{j} \sum_{s=0}^{K-k}(1-\delta)^{s} \frac{\left(\lambda^{k+s}(1-\hat{\theta})+\hat{\theta}\right)}{\left(\lambda^{s}(1-\hat{\theta})+\hat{\theta}\right)}\left(\tilde{\theta}_{k+s}^{i}\right)^{\sigma} .
\end{gathered}
$$

The relationship value $V_{k}$ increases in $k$, both because the conditional probability of a relationship being alive increases in $k$ and because expected revenues, which depend on $\tilde{\theta}_{k}$, also rise in $k$.

Finally, consider the standard (frictionless) case where the importer knows perfectly that the supplier will deliver a high-quality input (for example, after $\tilde{k}$ interactions, for large $\tilde{k}$ ). This case implies a $\tilde{\theta}_{k}=1$ for all periods, and the probability of a relationship being alive after $k$ periods is simply $(1-\delta)^{k}$. Expected 
profits from exporting are given by

$$
\begin{aligned}
V_{\tilde{k}}=\mathrm{E}\left[\Pi_{\tilde{k}}\right] & =\sum_{s=0}^{K-\tilde{k}}(1-\delta)^{s} \mathrm{E}\left[\pi_{s}^{i j} \mid \tilde{\theta}_{s}^{i}=1\right] \\
& =\frac{1-(1-\delta)^{K-\tilde{k}+1}}{\delta \sigma}\left(\tau p^{i i}\right)^{1-\sigma} A^{j}
\end{aligned}
$$

For maximum age $K \rightarrow \infty$, this expression converges to the standard sum of profits under CES in a frictionless world with exogenous death probability $\delta$.

\subsection{Solving for the Equilibrium}

In the two-country model, there are six equilibrium conditions (three for each country). To keep the equations tractable, it is useful to introduce some notation. We shorten the equation for domestic profits to:

$$
\mathrm{E}\left[\pi_{t, k}^{i i}\right]=\frac{1}{\sigma}\left(p_{t}^{i i}\right)^{1-\sigma} A_{t}^{i}=\frac{r_{t}^{i i}}{\sigma} A_{t}^{i}
$$

with $r_{t}^{i i}=\left(p_{t}^{i i}\right)^{1-\sigma}=\left(\frac{\sigma}{\sigma-1} c^{i} w_{t}^{i}\right)^{1-\sigma}$. We shorten expected profits from exporting in Equation (10) to:

$$
\mathrm{E}\left[\pi_{t, k}^{i j}\right]=\frac{\tilde{\theta}_{k}^{i}}{\sigma}\left(p_{t, k}^{i j}\right)^{1-\sigma} A_{t}^{j}=\frac{r_{t, k}^{i j}}{\sigma} A_{t}^{j},
$$

with $r_{t, k}^{i j}=\tilde{\theta}_{k}^{i}\left(p_{t, k}^{i j}\right)^{1-\sigma}=\tilde{\theta}_{k}^{i}\left(\frac{\tau}{\tilde{\theta}_{k}^{i}} p_{t}^{i i}\right)^{1-\sigma}$

Free entry First, free entry must hold in both countries, such that the expected sum of future profits of an entrant at time $t$ is equal to the fixed cost of entering 
production 25 We have:

$$
w_{t}^{i} f_{E}=\sum_{s=0}^{K} \operatorname{alive}_{s}^{i j}\left(\pi_{t+s, s}^{i i}+\pi_{t+s, s}^{i j}\right)
$$

where alive $_{k}$ is the probability that a relationship survives $k$ years, as previously. Now, replacing profits by expressions 18$)$ and $(19)$, we can rewrite to:

$$
w_{t}^{i} \sigma f_{E}=\sum_{s=0}^{K} \operatorname{alive}_{s}^{i j}\left(r_{t+s}^{i i} A_{t+s}^{i}+r_{t+s, s}^{i j} A_{t+s}^{j}\right)
$$

Isolating the first term of the sum, combining the two equations, and then solving for the home and foreign demand delivers:

$$
A_{t}^{i}=\frac{r_{t}^{i i}\left(w_{t}^{i} \sigma f_{E}-\Pi_{t, 1+}^{i}\right)-r_{t, 0}^{i j}\left(w_{t}^{j} \sigma f_{E}-\Pi_{t, 1+}^{j}\right)}{r_{t}^{i i} r_{t}^{j j}-r_{t, 0}^{i j} r_{t, 0}^{j i}},
$$

with $\Pi_{t, 1+}^{i}=\sum_{s=1}^{K}$ alive $e_{s}^{i j}\left(r_{t}^{i i} A_{t+s}^{i}+r_{t+s, s}^{i j} A_{t+s}^{j}\right)$ the sum of expected profits from period 1 onward.

Labor market clearing Second, labor markets in both countries need to clear. Call the mass of firms in country $i$ at time $t$ of age $k N_{t, k}^{i}$, and total labor in country $i L^{i}$. Then,

$$
L^{i}=N_{t, 0}^{i} f_{E}+\sum_{s=0}^{K} N_{t, s}^{i} c^{i}\left(\left(p_{t}^{i i}\right)^{-\sigma} A_{t}^{i}+\tau\left(p_{t, s}^{i j}\right)^{-\sigma} A_{t}^{j}\right)
$$

Solving for entry in period $t$ by isolating the first term of the sum delivers:

$$
N_{t, 0}^{i}=\frac{L^{i}-L_{P, t, 1+}^{i}}{f_{E}+c^{i}\left(\left(p_{t}^{i i}\right)^{-\sigma} A_{t}^{i}+\tau\left(p_{t, 0}^{i j}\right)^{-\sigma} A_{t}^{j}\right)},
$$

\footnotetext{
${ }^{25}$ As in Krugman (1980), we do not assume any fixed cost of exporting, so that any firm that enters also exports. In addition, we assume that if a trade relationship gets resolved, the firm also ceases to sell domestically. The latter assumption is mainly for tractability and could be relaxed.
} 
with $L_{P, t, 1+}^{i}=\sum_{s=1}^{K} N_{t, s}^{i} c^{i}\left(\left(p_{t}^{i i}\right)^{-\sigma} A_{t}^{i}+\tau\left(p_{t, s}^{i j}\right)^{-\sigma} A_{t}^{j}\right)$ the production labor used by all firms that are not new in countries $i$, respectively.

Balanced trade Balanced trade requires that income equals total expenditure (domestic consumption plus imports) at time $t$.

$$
w_{t}^{i} L^{i}=A_{t}^{i} \sum_{s=0}^{K}\left(N_{t, s}^{i} r_{t}^{i i}+N_{t, s}^{j} r_{t, s}^{j i}\right)
$$

There are two balanced budget conditions, and either would be sufficient to solve the model. However, for the numerical solution, it turns out to be helpful to use both equations in the minimization problem.

Aggregate price indices and aggregate quantities The price index at time $t$ is an aggregation of prices paid for all goods successfully supplied at time $t$, taking into account that delivery is only successful with probability $\tilde{\theta}_{k}$. Thus, we can derive the ideal price index as

$$
P_{t}=\left(\int_{\omega \in \Omega} p(\omega)^{1-\sigma} d \omega\right)^{\frac{1}{1-\sigma}}=\left(\sum_{s=0}^{\infty} \tilde{\theta}_{s} N_{t, s} p_{s}^{1-\sigma}\right)^{\frac{1}{1-\sigma}}
$$

We can also derive the aggregate consumption from CES imports as

$$
Q_{t}=\left(\int_{\Omega} q(\omega)^{\frac{\sigma-1}{\sigma}} d \omega\right)^{\frac{\sigma}{\sigma-1}}=\left(\sum_{s=0}^{\infty} \tilde{\theta}_{s} N_{t, s} q_{s}^{\frac{\sigma-1}{\sigma}}\right)^{\frac{\sigma}{\sigma-1}}
$$

Law of motion for number of relationships Finally, the law of motion of the number of relationships is directly determined by the survival probability:

$$
N_{t+1, s+1}^{i}=\operatorname{surv}_{s}^{i} N_{t, s}^{i}
$$


Normalizing the wage in country $i$ to 1 and given the calibrated parameters $\lambda^{i}$, $\hat{\theta}^{i}, \delta^{i}, \lambda^{j}, \hat{\theta}^{j}$, and $\delta^{j}$, we use these equilibrium conditions to solve for the unknowns $\left\{A_{t}^{i}, A_{t}^{j}, N_{t, k}^{i}, N_{t, k}^{j}, w_{t}^{j}\right\}$ in every period $t$ and for all ages $k$.

Solving the dynamic model We solve for the dynamic transition path of the model (from any arbitrary starting point) in the following way:

1. Guess a sequence of demand at home and abroad, $A_{t}^{i}, A_{t}^{j}$, and a sequence of the foreign wage $w^{j}$ for periods $t=1$ to $n$

2. Repeat until convergence:

(a) Solve for period 0 wage, $w_{0}^{j}$, home entry, $N_{0,0}^{i}$, and foreign entry, $N_{0,0}^{j}$ using the guesses and the initial distribution of relationships. Calculate new demand at home and abroad for period $0, A_{0}^{i, N}$ and $A_{0}^{j, N}$.

(b) Based on entry in period 0, calculate new distribution for period 1 and solve for wage, $w_{1}^{j}$, home entry, $N_{1,0}^{i}$, and foreign entry, $N_{1,0}^{j}$. Calculate new demand at home and abroad for period $1, A_{1}^{i, N}$ and $A_{1}^{j, N}$.

(c) Repeat for all periods 2 to $n$

(d) Update the guesses for $w^{j}, A_{t}^{i}$ and $A_{t}^{j}$ (for example, $A_{t}^{i, U}=0.95 A_{t}^{i}+0.05 A_{t}^{i, N}$ for all $t=1$ to $n$ )

The algorithm works well when using the steady-state values as initial guesses. Note that to calculate entry at period $t$, we need to know the demand and relative wage in all periods up to $t+K$. We set the demand and relative wage for all periods after period $n$ to their steady-state values. In our numerical exercises, we set the maximum number of periods $n=60$ to make sure that the economy converges back to steady state well before period $n$. 


\subsection{Taking care of partial year effects}

As shown in Bernard et al. (2017), it is crucial to control for the fact that a firm may sell less in its first year of exporting than theory predicts because of partial year effects. We address this issue in the following way. Assume that a relationship starts trading randomly in any given month, and assume that demand is uniformly distributed over calendar months. Then, a random relationship is expected to trade, on average, exactly half the value in its first year than otherwise predicted by theory.

To take this point into account, we therefore set $R_{t, 0}^{i j}=0.5 p_{0}^{i j} q_{t, 0}^{i j}$ in our baseline calibration. In the rest of the paper, we consistently take care of the partial year effects. In particular, when calculating the discounted sum of future profits in the free entry condition of firms, we assume that firms in their first year only have half the revenues and operating profits than the theory would predict otherwise.

When solving the general equilibrium model, we also need to take a stance on how the partial year effect maps into consumption. In principle, there are two options. First, in its first year, a firm could only sell half the standard CES quantity of its product to each consumer. Alternatively, in its first year, a firm could sell the standard CES quantity to half of the consumers. We make the second assumption, as it is more easily reconciled with the prices implied by the benchmark CES model of demand and also allows for the price level to be the aggregation of those prices.

For clarity of exposition, the derivations in the main text do not include the partial year effect correction, as it does not add to any of the intuition of the learning model. The full formulas are employed in the Python code and are available upon request. 


\section{Calibration and Counterfactuals}

In this section, we calibrate the model and present counterfactuals. Section 4.1 presents our calibration approach and its outcomes. In Section 4.2, we calculate the value of relationships across countries and demonstrate that the measure can explain relationship survival during the 2008-09 crisis. Section 4.4 presents two evaluations of the effects of shocks to the distribution of relationships on the probability of a successful delivery, prices, and total output.

\subsection{Matching with the data}

We employ an algorithm that searches for the parameter vector $(\delta, \hat{\theta}, \lambda)$ that minimizes the sum of squared differences between the moments in the data and those predicted by the model. As moments, we use the elements of the count and value distributions. We solve the following problem:

$\arg \min _{\delta, \hat{\theta}, \lambda} \beta \sum_{k=0}^{K}\left(\text { ageshare }_{k}-\widehat{\text { ageshare }}_{k}\right)^{2}+(1-\beta) \sum_{k=0}^{K}\left(\text { tradeshare }_{k}-\text { tradeshare }_{k}\right)^{2}$

where ageshare and tradeshare are the values predicted by the model, and $\widehat{\text { ageshare }}$ and tradeshare are taken from the data. We set $\beta=0.5$ and set the other parameters to $\sigma=3$ and $c=126$

We run this procedure for 10 major trading partners with significant exports to the United States ${ }^{27}$ For each country, we use information on eight cohorts- that is, on relationships that are one to eight years old $(K=8){ }^{28}$ The three parameters for each country are therefore selected by matching 16 moments in the model with

\footnotetext{
${ }^{26}$ Changes to $c$ have basically no effect on the estimated parameters.

${ }^{27}$ These are Canada, China, Germany, France, India, Japan, Korea, Mexico, Taiwan, and the United Kingdom.

${ }^{28}$ Eight is the largest number of cohorts for which we have information on all countries. We could add additional cohorts at the price of dropping some countries.
} 
their empirical counterparts. The parameter estimates are found in the left panel of Table 6.

How well do the model-implied distributions represent their empirical counterparts? Figure 7 shows that the calibrated model matches the underlying data well. China's trade, for example, is tilted toward new relationships, while Japan has more trade in longer-term relationships. As should be expected, the model matches the data less well when there are outliers. A case in point is Mexico, where in 2011 a large fraction of trade was in relationships that were exactly seven years old. The calibration adjusts parameters to accommodate the outlier at the cost of an inferior fit to the other moments of the value distribution. Similarly, outliers in middle-age relationships in Japan lead the model to over-predict the fraction of trade in long-term relationships in that country.

Would it suffice to only consider the exogenous death shock and abstract from learning? We address this question by running our calibration exercise on a restricted model where only $\delta$ is active and $\lambda$ is set to one (a frictionless world). The alternative model delivers an extremely poor fit to the data, as reported in Table 7. The table also compares the fully estimated model with versions where

either $\hat{\theta}$ or $\lambda$ is fixed across countries (and chosen optimally)- the sum of squared errors from Equation (29) is lowest by allowing all three parameters to vary across countries. Figure 8 plots the goodness of fit (the sum of squared errors) of the whole model against one where only $\delta$ matters and shows that only relying on exogenous relationship death to explain the data is insufficient. Hence, while $\delta$ is a central parameter for the value of long-term relationships, it can only be calibrated credibly when learning is active.

\subsection{The value of trade relationships}

Relationship values We can now quantify the value of relationships using the estimated parameters and Equation (16). We first return to Table6 to show some 
descriptive results. Column (4) reports the sum of expected profits from a new relationship $V_{0}$; column (5) reports the sum of expected profits from a relationship with a supplier that will deliver usable inputs with probability $1, V_{\tilde{k}}$; and column (6) reports the ratio between the values in columns (5) and (6).

Consider some examples from Table 6. New relationships with the United Kingdom (2) and France (3.1) have the lowest value, mostly because they rank lowest in $\hat{\theta}$. A new relationship is the most valuable with Taiwan (10.9), which has relatively high estimates for $\lambda$ and $\hat{\theta}$ combined with a moderate estimate for $\delta$. The value of an old relationship $V_{\tilde{k}}$ maps directly into $\delta$, as it does not depend on $\lambda$ and $\hat{\theta}$. The expected sum of profits from an established relationship are therefore lowest for China (33.5) and Canada (45.2) and highest for France (242.6) and Mexico (238).

According to our estimates, relationships are most valuable in France (where an established relationship has a sum of expected profits 79 times higher than a new relationship) and the United Kingdom (33.1). Both countries feature low $\hat{\theta}$ that depress the value of new relationships. We find the lowest relationship values for China (5.1) and Taiwan (5.9). Both jurisdictions have high $\hat{\theta}$, implying high profits from new relationships, and moderate to high $\delta$, implying low profits from old relationships. Across all countries, the median value of a long-term relationship is 13.9 times that of a new relationship. The large size of these estimates should not be surprising, given our empirical findings that long-term relationships foster higher trade as well as greater survival.

Importantly, countries with higher relationship values are not simply those with fewer long-term relationships: both Korea and China have nearly identical shares of long-term relationships ( $\approx 11$ and 13 percent, respectively), but they differ greatly in the value of a relationship (5.1 versus 14.2). Based on our calibration, China has mostly short-term relationships because of a high $\delta$, while Korea has many short-term relationships because of a somewhat low $\hat{\theta}$ and a moderate $\delta$. The high $\delta$ for China implies that long-term relationships are not very valuable, as they 
tend to die quickly for exogenous reasons 29 The low $\hat{\theta}$ for Korea leads to a low value of new relationships. At the same time, Korea's $\delta$ is not that high, making long-term relationships more valuable. Put together, these parameter differences imply that Korea has a much higher inherent value of relationships than China.

The reverse holds as well: jurisdictions with similar values of old relationships need not have similar age distributions. Column (5) of the table shows that old relationships with China and Taiwan are similarly valuable, even though in the data, their shares of old relationships are very different. The model generates a high Taiwanese share of old relationships via both a fairly high $\hat{\theta}(0.22)$ and moderate values of $\lambda(0.36)$ and $\delta(0.19)$, while the low Chinese share of old relationships comes from a very high $\delta(0.37)$ and low $\lambda(0.31)$.

Tracking value as relationships age We next illustrate how the expected profits from a relationship change with relationship age. Figure 9 plots $V_{k}$ for three economies - China, Japan, and Taiwan - based on their estimated parameters $\lambda$, $\delta$, and $\hat{\theta}$. The starting point of the lines are given by Equation (15) - the value of a new relationship, $V_{0}$ - while the end points can be approximated by Equation (17), the value of an old relationship, $V_{\tilde{k}}$. First, note that because of learning, the sum of expected profits from a relationship strictly increases in the relationship's age.

Consider China and Japan. A new relationship has about the same expected profits in both countries. However, in the long run, relationships with Japan are much for valuable, as relationships are more stable (lower $\delta$ ). Now consider Taiwan and Japan. Japan's lower $\hat{\theta}$ implies a much lower value of expected future profits from a new relationship. In the long run, however, all relationships that are still alive are with patient suppliers. So after six years, $\hat{\theta}$ and $\lambda$ hardly have any effect on the relationship value, and the key determinant becomes $\delta$. As Taiwan and

\footnotetext{
${ }^{29}$ More specifically, the model assigns a high $\delta$ to China, as in the data even old relationships with China die relatively frequently.
} 
Japan have about the same $\delta$, their relationship values converge to roughly the same number.

\subsection{Using Relationship Values to Explain Survival in 2008- 09}

During the 2008-09 crisis, international trade plummeted. Besides the large decline in aggregate trade, the crisis also triggered changes to the number and the age structure of relationships.

The first line of Table 8 shows that the number of relationships declined during the crisis: compared with 2008, there were 7 percent fewer relationships in 2009. Much of the story is a decrease in new relationship formation: in 2009, there were 15 percent fewer relationships formed. But we have shown trade volumes are more concentrated in continuing relationships, and those fell too: the number of continuing relationships dropped by 6 percent from 2008 to 2009.

We can use our definition of relationship value, together with other explanatory variables, to predict which relationships survived the 2008-09 crisis. For the dependent variable, we use the average survival probability for each country-relationship age group over the years from 2006 to 2011 30 As before, the survival probability is the percentage of relationships of age $k$ in year $t$ that survived to year $t+1$. On the right hand side, we include a variety of regressors and fixed effects to understand which relationships survived.

Table 9 presents our results. We first regress average survival on a dummy

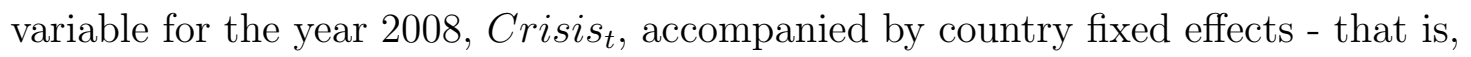
the crisis dummy captures survival from 2008 to 2009. As can be seen from column (1) (and consistent with Table 8), the average survival probability of relationships declined substantially during the crisis. Next, we demonstrate that our measure of relationship value can predict relationship survival during that period. Column (2)

\footnotetext{
${ }^{30}$ For disclosure purposes, we limit to exporting countries with more than 100 relationships.
} 
shows the results from regressing the survival probability on an interaction between the Crisis $_{t}$ dummy and our measure of relationship value, $V_{c k}$, including year, age, and country fixed effects. The strong positive correlation of this interaction term demonstrates that the more valuable relationships are the ones most likely to survive. We also include a specification with year and country-age fixed effects (column 3) that gives the same result.

Macchiavello and Morjaria (2015) show that in the case of Kenya, the value of a relationship increases with age. An interesting question, therefore, is whether our measure for the value of a relationship affects survival beyond a pure age effect. In fact, even when accounting for the possibility of a separate interaction between the crisis dummy and age, as in Column (4), the result holds: that is, even among relationships that are the same age, the relationships that are more valuable, according to our measure, are more likely to survive. We do not find that older relationships are more likely survive (given the lack of significance of the crisis-age interaction term).

Larger relationships should, all else equal be more likely to survive such a shockfor this reason, we also recreate our results including log average trade within a country-age group as an additional explanatory variable. All results continue to be highly significant, as shown in columns (5)-(7). In sum, our calibrated model of relationship values successfully predicts which relationships survived the 2008-09 crisis.

\subsection{Quantitative Evaluation}

Our last step is to describe the quantitative evaluation of the model. We explore the importance of relationships for aggregate welfare with two experiments. In the first experiment we erase the memory of all importers about previous interactions with their suppliers. In the second experiment, we destroy all relationships between importers and their foreign suppliers. These two experiments provide 
a quantification of how valuable relationships are in welfare terms when the full dynamics of the economy are taken into account.

In each experiment, we let firms respond optimally, studying the transition path back to the steady state of the economy. We run the experiments separately for each of the top 10 trading partners of the United States 31

Reset of all trade relationships The first experiment wipes out all established relationships and replaces them with the same number of new relationships 32 We first discuss outcomes for two illustrative countries, the United Kingdom and Germany. As can be seen in Table 2, Germany tends to have older relationships, while Table 6 shows that Germany has a higher $\lambda$ and lower $\hat{\theta}$ compared with the United Kingdom. Reactions of different variables to the relationship reset are shown in Figure 10.

In both countries, consumption drops substantially and takes several years to recover, but the recovery paths for the United Kingdom and Germany differ. Why? Relationships tend to die less quickly in Germany than in the United Kingdom, and Germany therefore has more "relationship capital" in steady state. Consequently, in the experiment, prices (relative to their steady-state level) spike by more in Germany after erasing all memory of previous interactions, and a larger fraction of consumption is lost. At the same time, rebuilding relationships takes longer, so recovery is slower in Germany than in the United Kingdom. All told, Germany loses about 29 percent of its annual steady-state level of consumption over the transition, while the United Kingdom loses 16 percent of its annual consumption level. Across all countries, the average loss in the transition back to a steady state

\footnotetext{
${ }^{31}$ More specifically, we take the calibration for each country and study the experiment by solving the symmetric case. Although we can solve for asymmetric cases in principle, the algorithm does not always converge. It would also be interesting to solve a multi-country version of the model. However, given the large number of state variables, we are only able to solve the two-country version.

${ }^{32} \mathrm{As}$ we only wipe out the memory from these relationships, we assume that they are not affected by the partial year effect. That is, we distinguish between relationships that lost their memory (no partial year effect) and relationships that are truly new (with partial year effects).
} 
is about 48 percent of the annual steady-state level of consumption, with China losing the least (13 percent) and Mexico losing the most (190 percent) ${ }^{33}$ The set of country-level results is shown in the left panel of Table 10 .

Destruction of all trade relationships In the second experiment all preexisting relationships are wiped out, so the economy has to use substantial amounts of labor to pay for the creation of new relationships. Consequently, in this scenario, losses are larger. Results, shown in Figure 11, are similar to those in experiment 1. The main difference is that consumption drops much more initially as both countries shift resources into relationship creation. However, this additional drop is short-lived, and, in later years, the recovery under experiment 2 looks very similar to that of experiment 1.

In experiment 2, welfare losses are higher, but the ranking of countries is basically unaffected. China still loses the least (32 percent of steady-state consumption), whereas Mexico still loses the most (223 percent). In addition, the ordering of Germany and the United Kingdom remains the same, with losses of 51 percent and 31 percent of consumption, respectively. The average loss is 70 percent. The full set of country-level results is shown in the right panel of Table 10.

To summarize the results of the experiments, relationships represent a type of knowledge capital. Losing that capital is costly for an economy, implying a large drop in welfare on impact and substantially lower levels of consumption on the transition path. Relationship disruptions have a significant impact on firm performance, and thereby on welfare.

\footnotetext{
${ }^{33}$ Part of the reason Mexico loses so much can be seen in Figure 8. Mexico has an outlier in six-year relationships, with an extremely high level of trade. The model calibration takes this into account by assigning Mexico both a very low $\hat{\theta}$ and a low $\delta$ (see Table 6), causing long-term relationships to be extremely valuable.
} 


\section{Conclusions}

Relationships between importers and exporters are the core of international trade transactions. This paper presents new facts on these relationships and develops a model, building on Araujo et al. (2016), to quantify the role of learning in international trade. The model fits our empirical findings well: trade increases within successful relationships over time, relationship survival increases over time, and countries differ systematically in their count and value distributions in ways our model can capture. Our estimated relationship values are good predictors of which relationships survive during the 2008-09 crisis.

Our experiments generate substantial cross-country heterogeneity in trade dynamics. In the short run, shocks to entry have the strongest effects on countries, like China, that are tilted toward relationships of short duration. In the medium run, however, entry shocks have a greater effect on countries that rely more on longer-term relationships, like Japan. This heterogeneity has implications, for example, for the study of trade policy. Our model suggests that the evolution of trade following Free Trade Agreements will depend on how trade is spread across relationships of different ages. At the same time, it implies that disruptions to relationships, such as from increased protectionism, have significant welfare effects. More generally, our analysis suggests that to capture the dynamics of aggregate trade, one needs to account for the differences in the dynamics of relationship-level trade across countries.

\section{References}

Albornoz, Facundo, Héctor F Calvo Pardo, Gregory Corcos, and Emanuel Ornelas, "Sequential Exporting," Journal of International Economics, 2012, 88 (1), 17-31.

Alessandria, George and Horag Choi, "Establishment heterogeneity, exporter 
dynamics, and the effects of trade liberalization," Journal of International Economics, 2014, 94 (2), 207-223.

_, _, and Kim J Ruhl, "Trade adjustment dynamics and the welfare gains from trade," Technical Report, National Bureau of Economic Research 2014.

Alvarez, Fernando and Robert E Lucas, "General equilibrium analysis of the Eaton-Kortum model of international trade," Journal of Monetary Economics, 2007, 54 (6), 1726-1768.

Antràs, Pol, "Firms, Contracts, and Trade Structure," Quarterly Journal of Economics, 2003, 118 (4), 552-580.

_ and C Fritz Foley, "Poultry in Motion: A Study of International Trade Finance Practices," Journal of Political Economy, 2015, 123 (4).

- and Elhanan Helpman, "Global Sourcing," Journal of political economy, 2004, $112(3), 691-719$.

Araujo, Luis F, Giordano Mion, and Emanuel Ornelas, "Institutions and export dynamics," Technical Report, National Bank of Belgium 2012.

_ , _, and _, "Institutions and Export Dynamics," Journal of International Economics, 2016, 98C, 2-20.

Arkolakis, Costas, Theodore Papageorgiou, and Olga Timoshenko, "Firm Learning and Growth," Review of Economic Dynamics, forthcoming.

Atkeson, Andrew and Ariel Tomas Burstein, "Innovation, Firm Dynamics, and international Trade," Journal of Political Economy, 2010, 118 (3), 433-484.

Bastos, Paulo, Daniel Dias, and Olga Timoshenko, "Learning, Prices and Firm Dynamics," Mimeo 2015.

Benguria, Felipe, "The matching and sorting of exporting and importing firms: theory and evidence," 2015. University of Kentucky, mimeo. 
Bernard, Andrew B, Andreas Moxnes, and Karen Helene Ulltveit-Moe, "Two-sided Heterogeneity and Trade," Review of Economics and Statistics, forthcoming.

_, Esther Ann Bøler, Renzo Massari, Jose-Daniel Reyes, and Daria Taglioni, "Exporter dynamics, firm size and growth, and partial year effects," American Economic Review, 2017, 107 (10), 3211-3228.

_, J Bradford Jensen, and Peter K Schott, "Importers, Exporters and Multinationals: A Portrait of Firms in the US that Trade Goods," in "Producer dynamics: New evidence from micro data," University of Chicago Press, 2009, pp. $513-552$.

Besedeš, Tibor, "A Search Cost Perspective on Formation and Duration of Trade," Review of International Economics, 2008, 16 (5), 835-849.

- and Thomas J Prusa, "Product Differentiation and the Duration of U.S. Import Trade," Journal of International Economics, 2006, 70 (2), 339-358.

Blum, Bernardo S, Sebastian Claro, and Ignatius J Horstmann, "Occasional and Perennial Exporters," Journal of International Economics, 2013, 90 (1), 65-74.

Carballo, Jerónimo, "Global Sourcing under Uncertainty," 2016. University of Colorado, mimeo.

_ , Gianmarco IP Ottaviano, and Christian Volpe Martincus, "The Buyer Margins of Firms' Exports," Discussion Paper 9584, CEPR 2013.

Chaney, Thomas, "The Network Structure of International Trade," American Economic Review, 2014, 104 (11), 3600-34.

Coase, Ronald H, "The Nature of the Firm," Economica, 1937, \& (16), 386-405. 
Eaton, Jonathan and Samuel Kortum, "Technology, Geography, and Trade," Econometrica, 2002, 70 (5), 1741-1779.

_, Marcela Eslava, Cornell J Krizan, Maurice Kugler, and James Tybout, "A Search and Learning Model of Export Dynamics," 2014. Mimeo.

_, Samuel Kortum, Brent Neiman, and John Romalis, "Trade and the Global Recession," The American Economic Review, 2016, 106 (11), 3401-3438.

Egan, Mary Lou and Ashoka Mody, "Buyer-Seller Links in Export Development," World Development, 1992, 20 (3), 321-334.

Grossman, Sanford J and Oliver D Hart, "The Costs and Benefits of Ownership: A Theory of Vertical and Lateral Integration," Journal of Political Economy, 1986, 94 (4), 691-719.

Heise, Sebastian, "Firm-to-Firm Relationships and Price Rigidity: Theory and Evidence," Mimeo 2015.

_, Justin R Pierce, Georg Schaur, and Peter K Schott, "Trade Policy and the Structure of Supply Chains," Technical Report, Mimeo 2015.

Impullitti, Giammario, Alfonso A Irarrazabal, and Luca David Opromolla, "A Theory of Entry into and Exit from Export Markets," Journal of International Economics, 2013, 90 (1), 75-90.

Jovanovic, Boyan, "Selection and the Evolution of Industry," Econometrica, 1982, $50(3), 649-670$.

Kamal, Fariha and Asha Sundaram, "Buyer-seller relationships in international trade: Do your neighbors matter?," Journal of International Economics, 2016, 102, 128-140.

_ and Ryan Monarch, "Identifying foreign suppliers in US import data," Review of International Economics, forthcoming. 
Kaufmann, Daniel, Aart Kraay, and Massimo Mastruzzi, "The Worldwide Governance Indicators: Methodology and Analytical Issues," Policy Research Working Paper Series 4978, The World Bank 2010.

Krautheim, Sebastian, "Heterogeneous firms, exporter networks and the effect of distance on international trade," Journal of International Economics, 2012, $87(1), 27-35$.

Krizan, C.J., "The Nuts and Bolts of International Trade Transactions: A Data User's Primer," 2012. U.S. Census Center for Economic Studies, mimeo.

Krugman, Paul, "Scale economies, product differentiation, and the pattern of trade," The American Economic Review, 1980, 70 (5), 950-959.

Macchiavello, Rocco and Ameet Morjaria, "The value of relationships: evidence from a supply shock to Kenyan rose exports," The American Economic Review, 2015, 105 (9), 2911-2945.

Monarch, Ryan, "It's Not You, It's Me: Breakups in U.S.-China Trade Relationships," Working Paper 14-08, U.S. Census Center for Economic Studies 2014.

Pierce, Justin R. and Peter K. Schott, "The Surprisingly Swift Decline of U.S. Manufacturing Employment," Working Paper 18655, National Bureau of Economic Research December 2012.

Rauch, James E, "Business and Social Networks in International Trade," Journal of Economic Literature, 2001, pp. 1177-1203.

- and Joel Watson, "Starting Small in an Unfamiliar Environment," International Journal of Industrial Organization, 2003, 21 (7), 1021-1042.

_ and _ , "Network Intermediaries in International Trade," Journal of Economics Es Management Strategy, 2004, 13 (1), 69-93. 
Ruhl, Kim J, "The international elasticity puzzle," Mimeo 2008.

- and Jonathan L Willis, "New Exporter Dynamics," International Economic Review, 2017, 58 (3), 703-726.

Schmidt-Eisenlohr, Tim, "Towards a theory of trade finance," Journal of International Economics, 2013, 91 (1), 96 - 112.

Timoshenko, Olga A, "Learning versus sunk costs explanations of export persistence," European Economic Review, 2015, 79, 113-128.

_, "Product switching in a model of learning," Journal of International Economics, 2015, 95 (2), 233-249.

\section{A Figures}

Figure 1: Count and Value Distributions, 2011

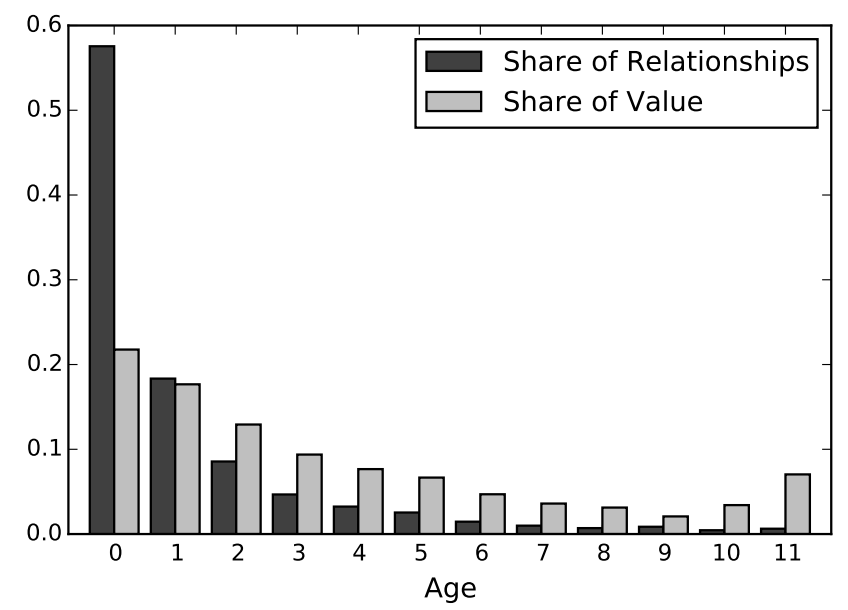

Note: This figure plots the count distribution and the value distribution for all U.S. imports in 2011. The count distribution is the distribution of relationship counts over different ages. The value distribution is the distribution of trade values across relationships of different ages. Age 11 includes all relationships that are 11 years or older. 
Figure 2: Distribution of Relationship Age and Value Shares, 2011

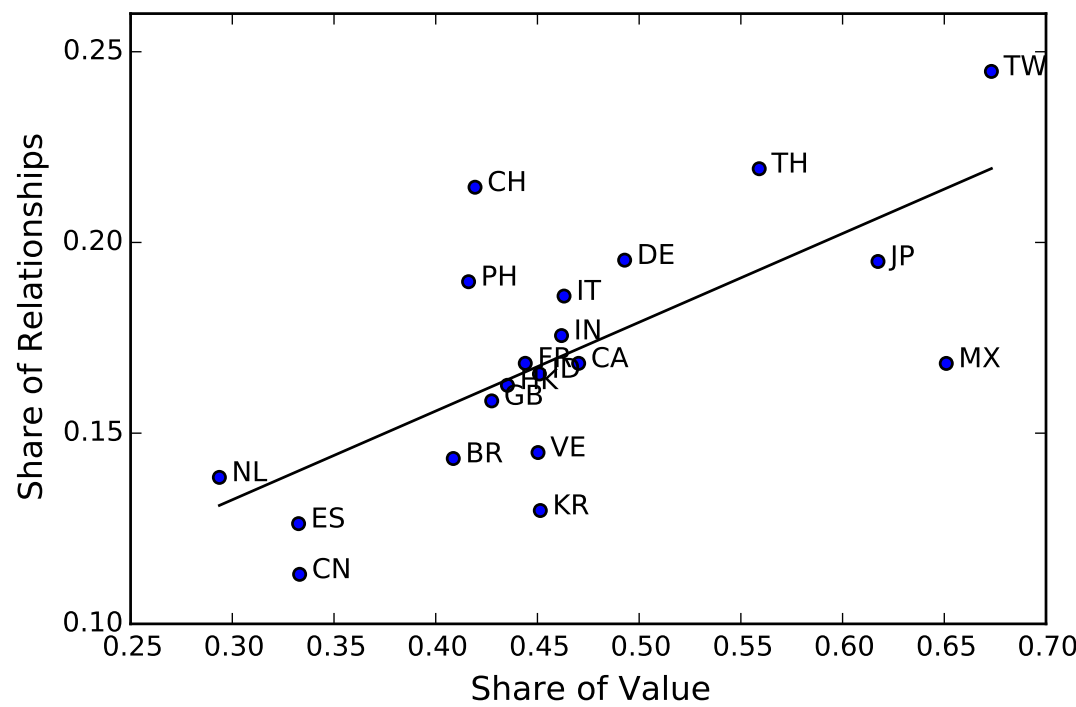

Note: This figure plots the share of long-term (three or more years) relationships against the share of trade in long-term relationships for the top 20 U.S. trading partners $\left(R^{2}=\right.$ $0.47)$. 
Figure 3: Evolution of Trade within a Relationship

Panel A: All relationships

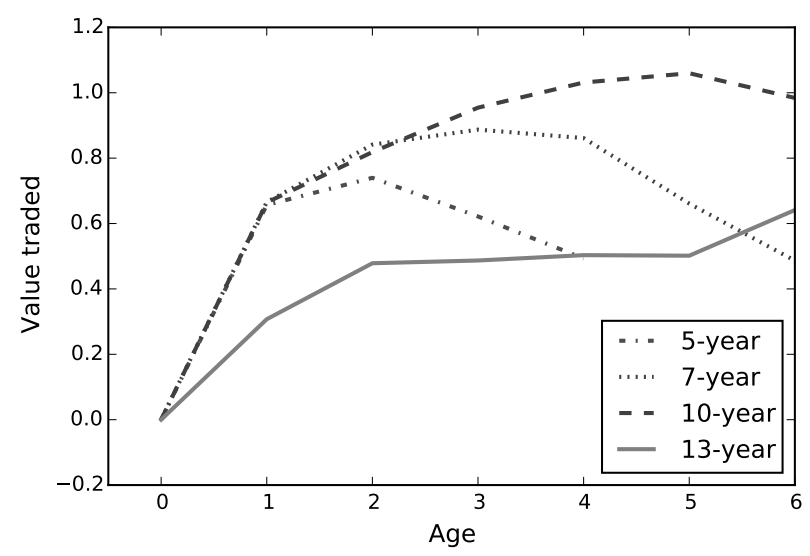

Panel B: Relationships that Began in the First Quarter

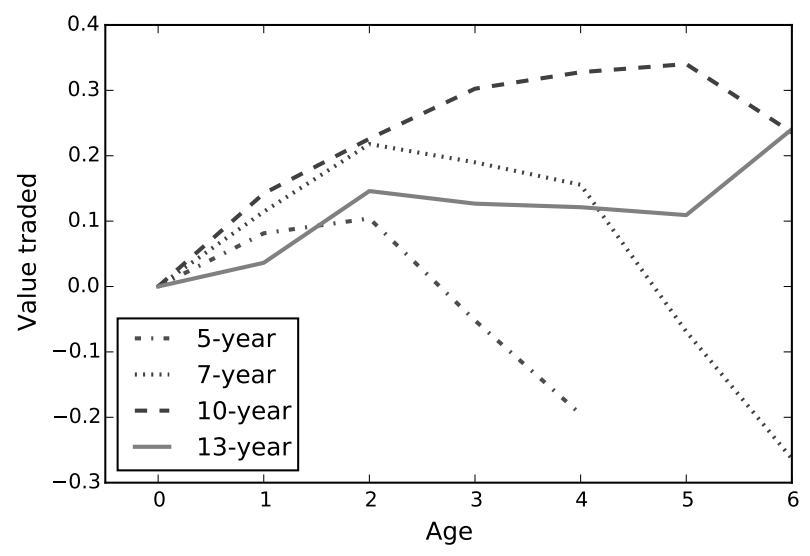

Note: These figures plot coefficients from regressions of traded value on relationship age dummies, run separately for relationships that lasted 5, 7, 10, and 13 years. Panel A shows results for all relationships. Panel B shows results for relationships that started trading between January and March, in order to account for "partial year effects". 
Figure 4: Relationship Survival Probabilities

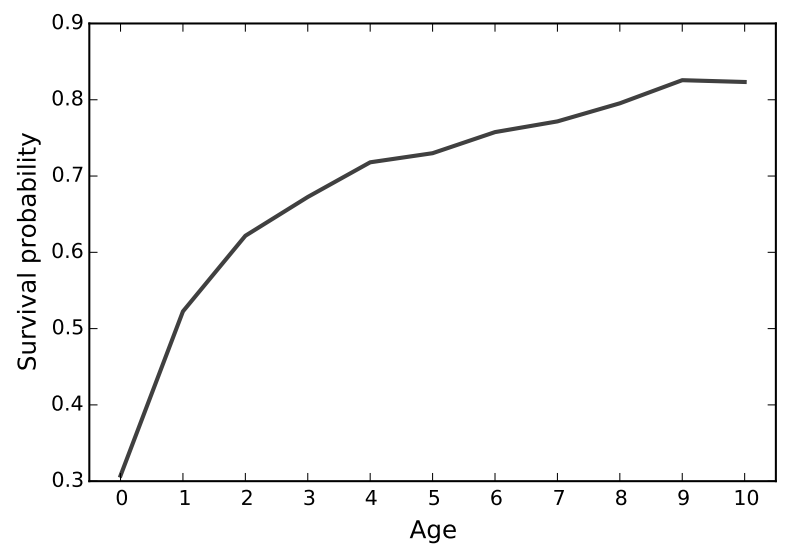

Note: This figure plots the conditional survival probability by age in 2011; that is, the share of relationships of age $k$ that survive to age $k+1$.

Figure 5: Survival Function

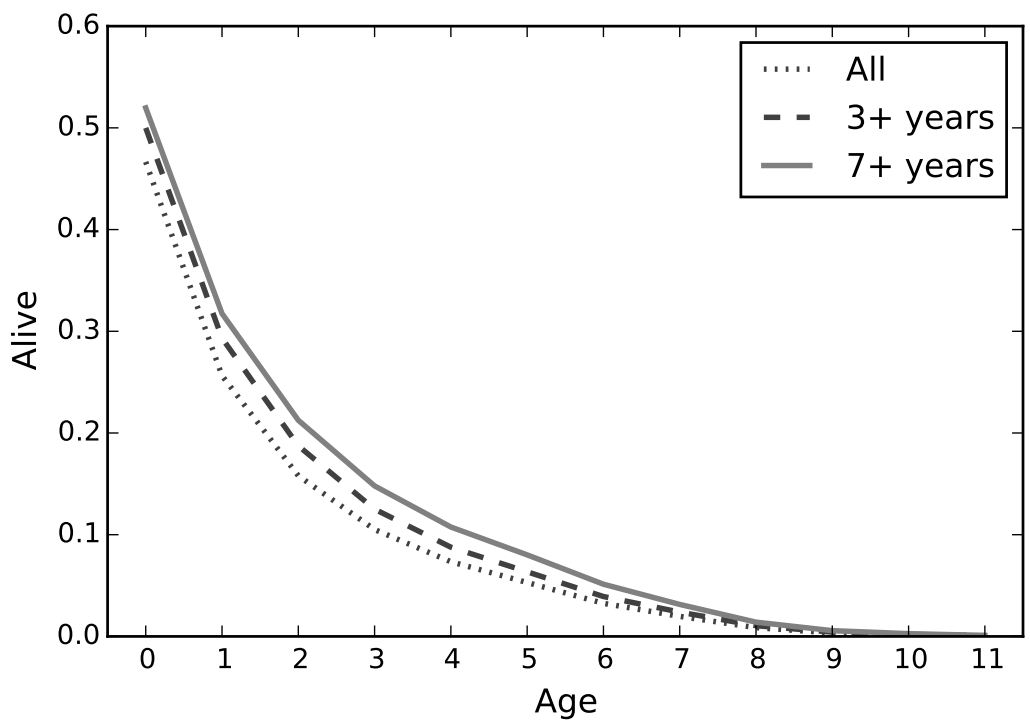

Note: This figure plots the survival function based on estimates from the Cox proportional hazard model for all relationships, firms that are at least three years old, and firms that are at least seven years old. 
Figure 6: Delivery Probabilities

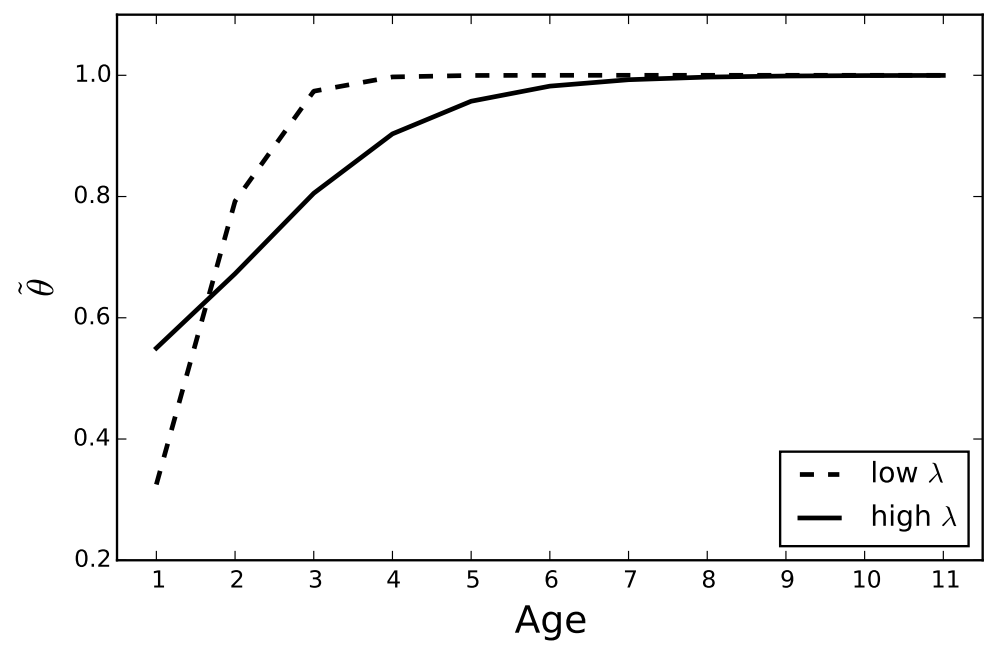

Note: This figure illustrates the role of $\lambda$ for $\tilde{\theta}_{k}$, the probability of an additional successful transaction following $k$ periods of trade. $\lambda$ takes the values 0.1 and 0.4 . $\hat{\theta}$ is set at 0.25 . 
Figure 7: Count and Value Distributions, Model vs. Data
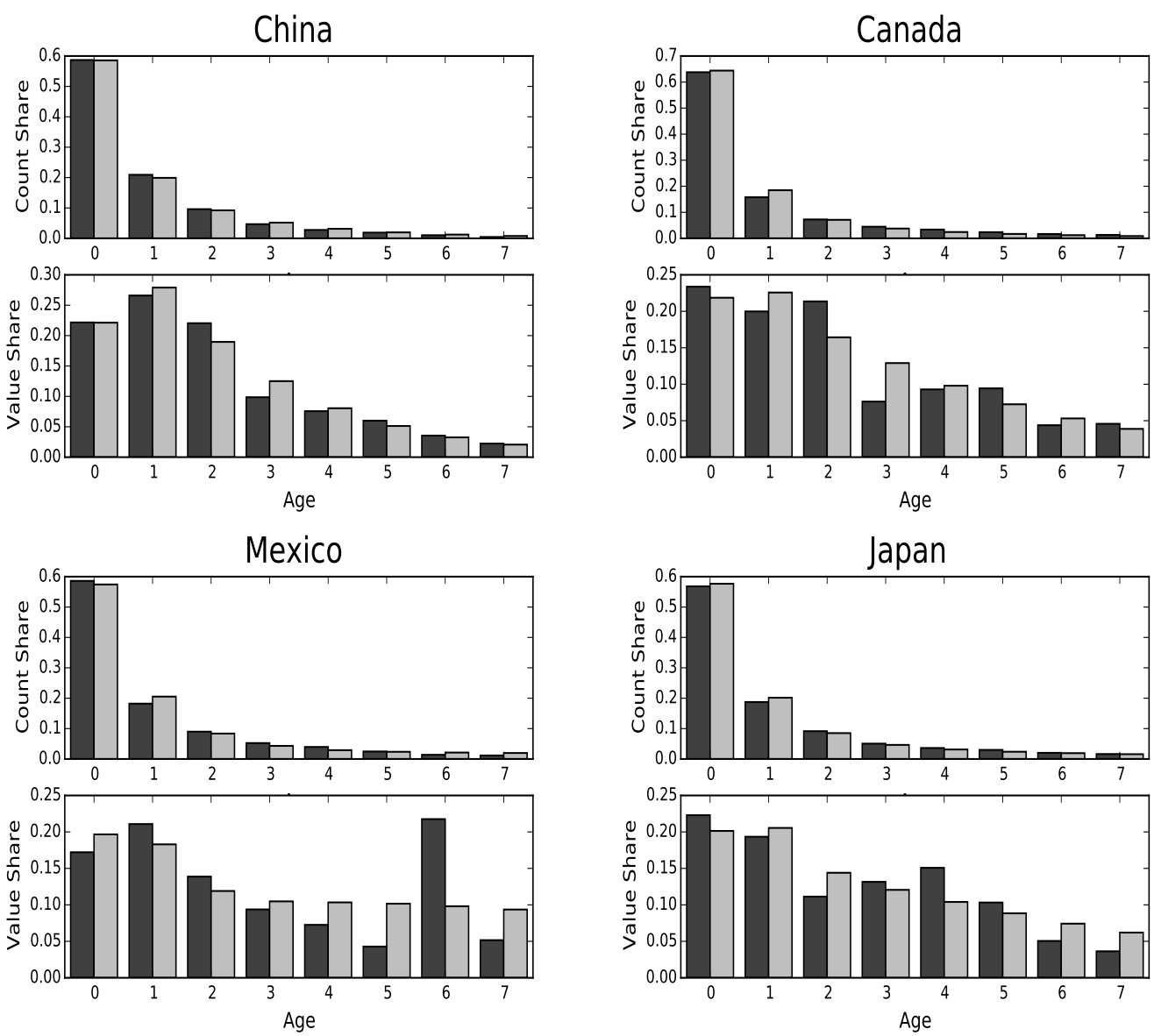

Note: This figure shows the count and value distributions for four countries. The dark bars represent data moments, while the light bars show moments from the calibrated model. 
Figure 8: Count and Value Distributions, Model vs. Data, All Countries

Panel A: Full model

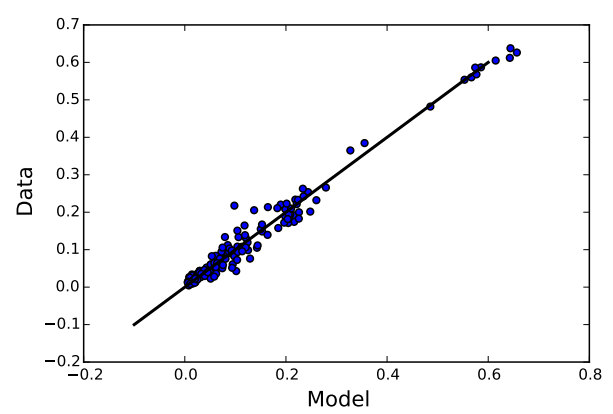

Panel B: only $\delta$

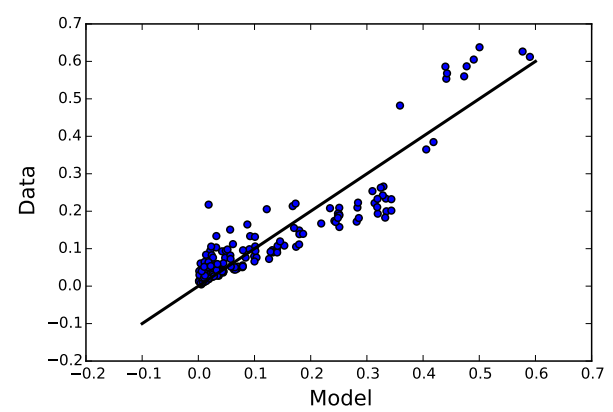

Note: These figures plots the data moments against the model moments for all 10 countries. Panel A shows the full model. Panel B shows results when only the dissolution shock $\delta$ is active; that is, $\lambda=1$. 
Figure 9: Expected Profits and Relationship Age

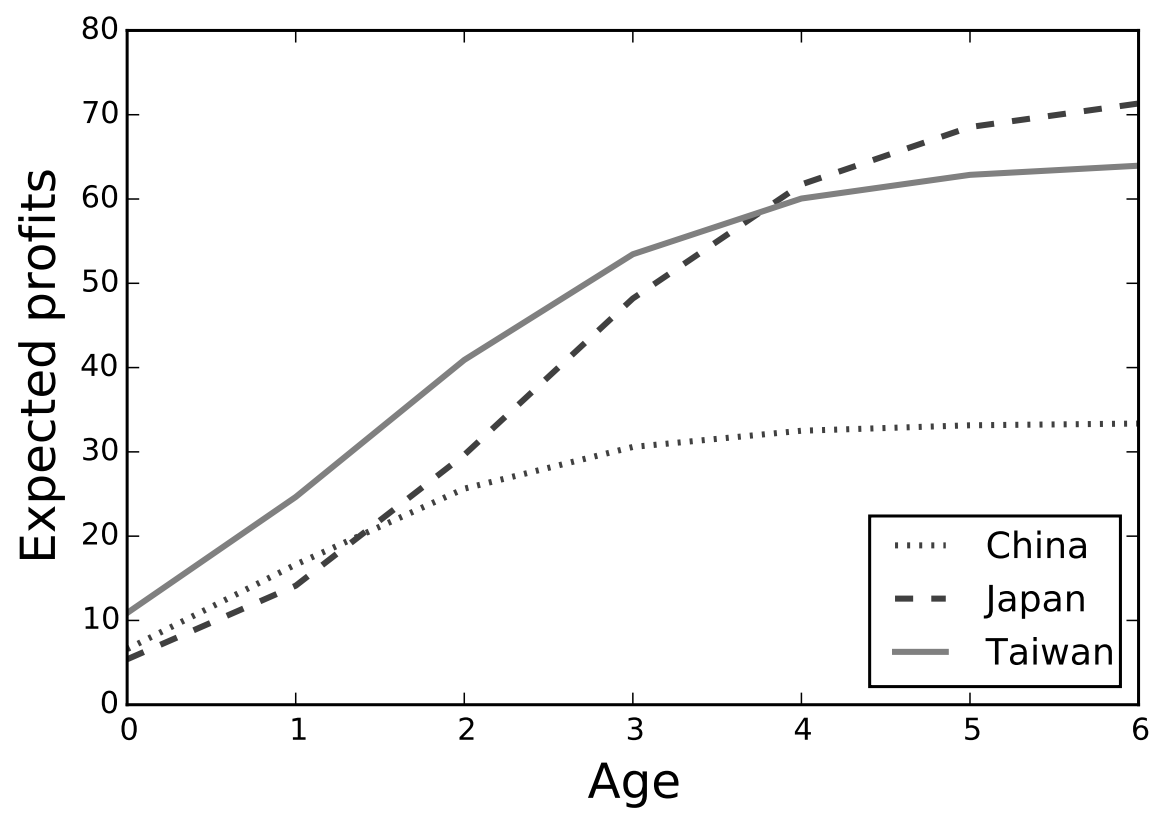

Note: This figure plots the expected sum of future profits at age $k$ for China, Japan, and Taiwan for their estimated $\lambda, \delta$, and $\hat{\theta}$. The starting point is given by Equation (D.6), while the end point can be approximated by Equation (17). 
Figure 10: Experiment 1: Erasing All Memory

Panel A: Average Success Probability

Panel B: Price Indices
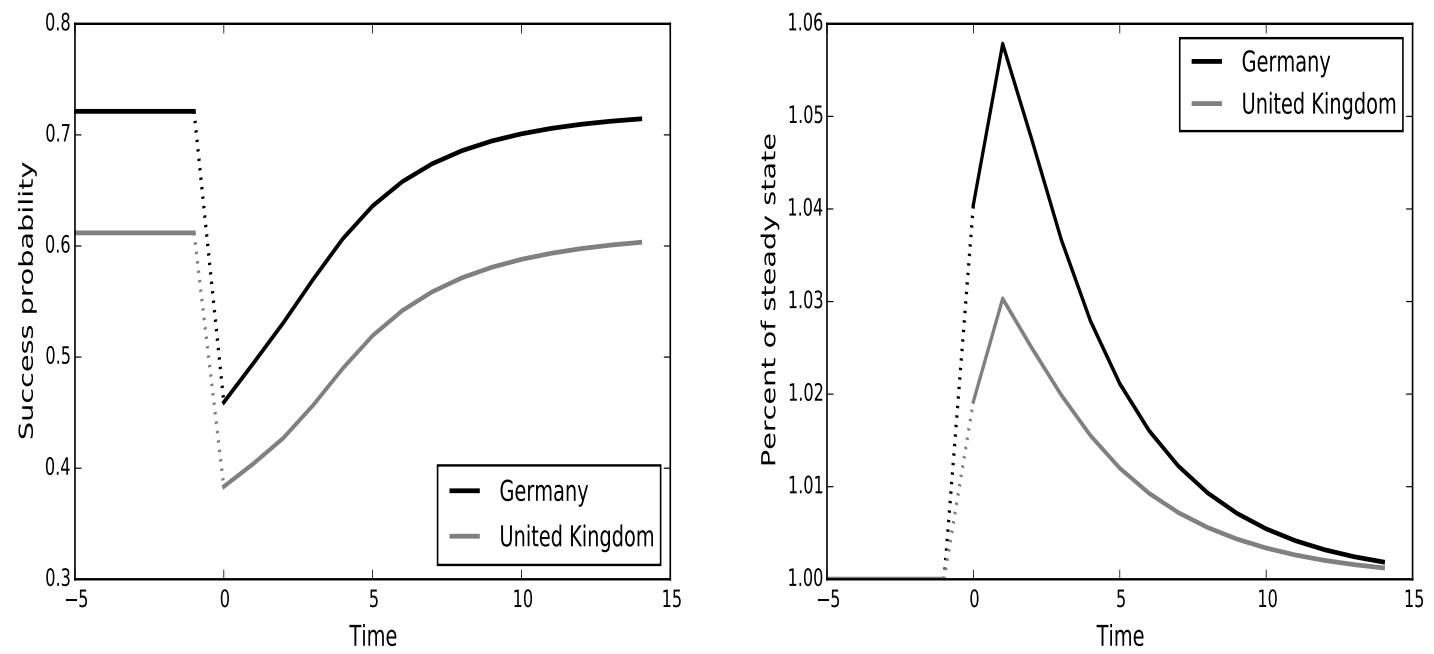

Panel C: Mass of Relationships

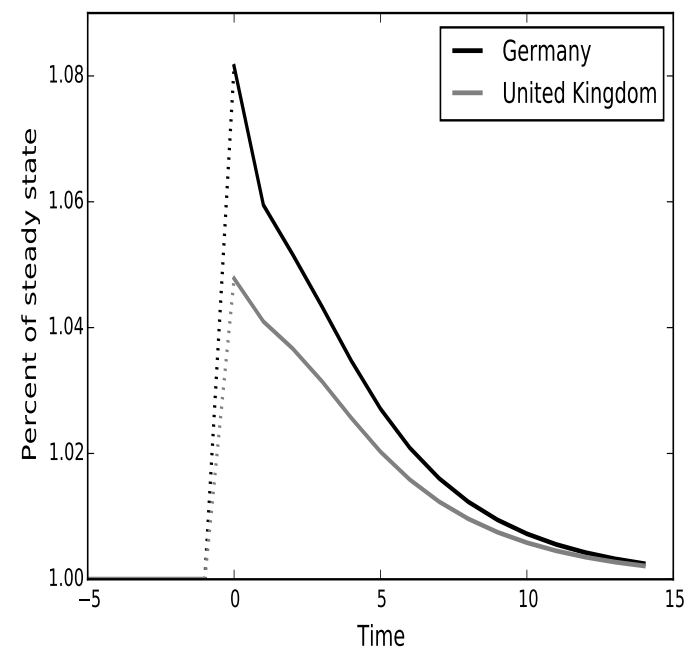

Panel D: Total Output

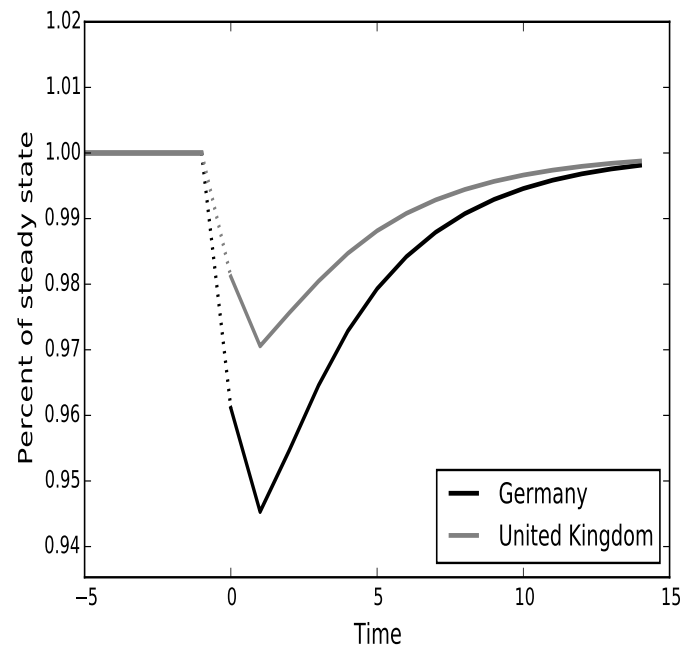

This figure shows results from the experiment where all relationships are "reset" to new for Germany and the United Kingdom. 
Figure 11: Experiment 2: Destruction of Relationships

Panel A: Average Success Probability

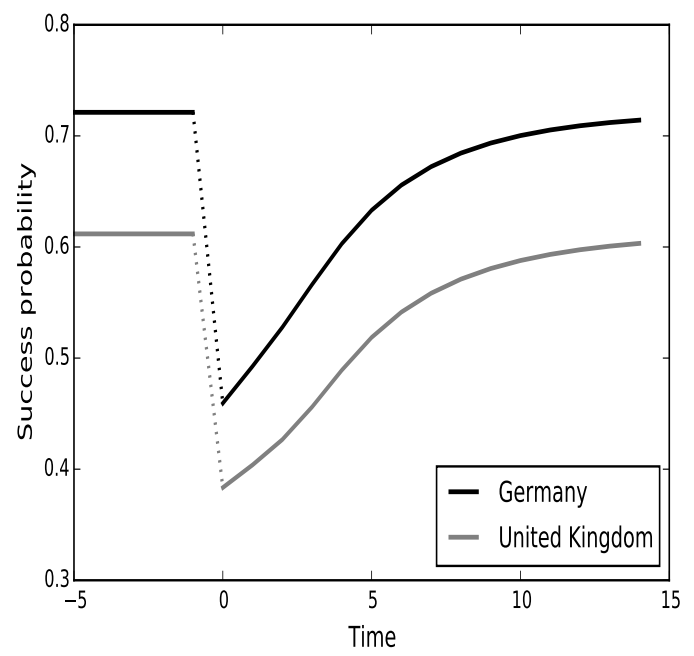

Panel C: Mass of Relationships

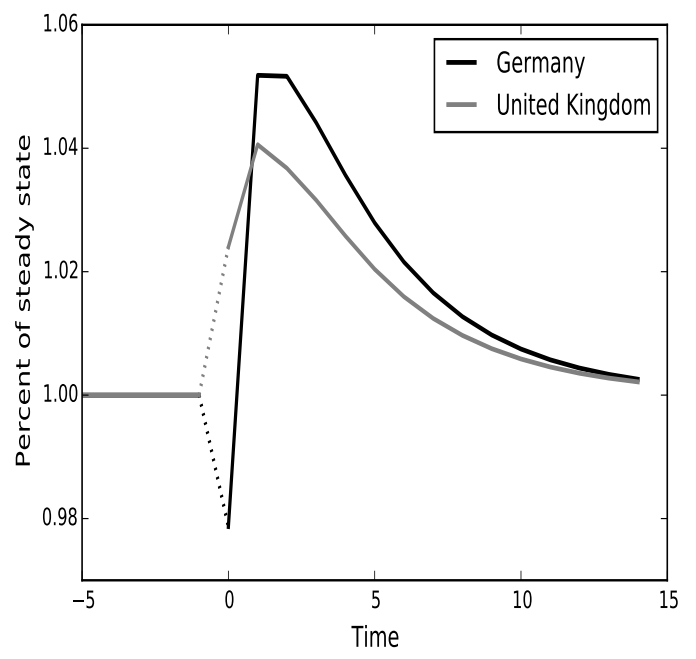

Panel B: Price Indices

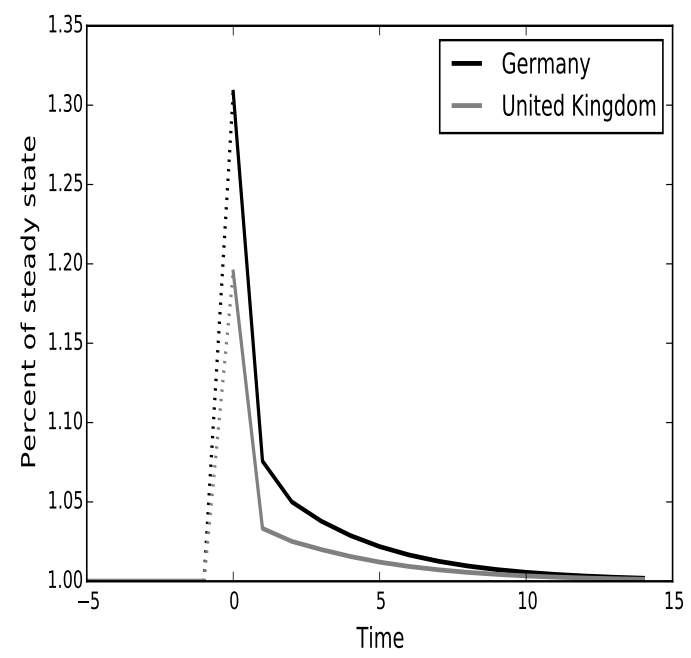

Panel D: Total Output

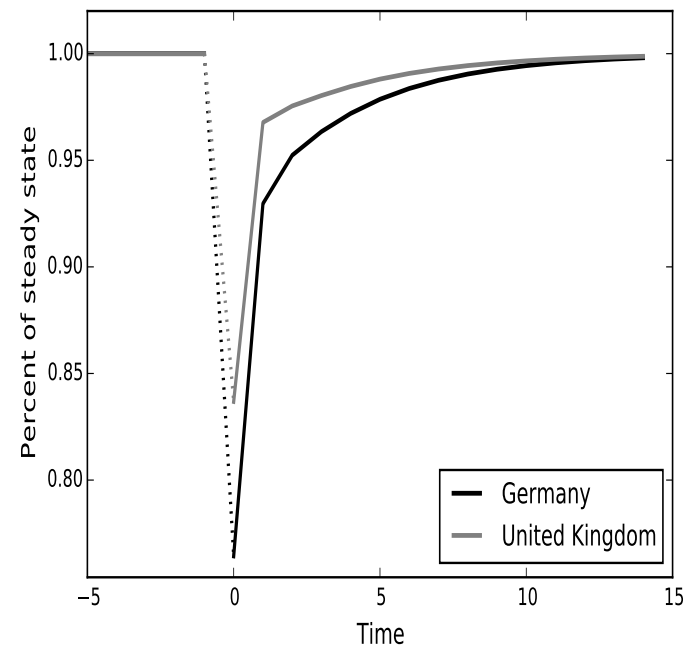

This figure shows results from the experiment where all existing relationships are destroyed for Germany and the United Kingdom. 


\section{B Tables}

Table 1: Relationship Structure of U.S. Imports, 2011

\begin{tabular}{lccc}
\hline & New & 1-2 Years & 3 or More Years \\
\hline Share of Relationships & 57.6 & 26.9 & 15.6 \\
Share of Trade & 21.8 & 30.6 & 47.6 \\
\hline
\end{tabular}

Note: For this table, a relationship is defined as a U.S. importing firm transacting with a non-U.S. exporting firm. A new relationship is one that is not found in any previous year of data.

Table 2: Relationship Structure of U.S. Imports, 2011

\begin{tabular}{lclc}
\hline \multicolumn{2}{c}{$\begin{array}{c}\text { Counts, } \\
\text { 3+ Year Relationships }\end{array}$} & $\begin{array}{c}\text { \% Trade, } \\
\text { Year Relationships }\end{array}$ \\
\hline China & 0.11 & Netherlands & 0.29 \\
Spain & 0.13 & Spain & 0.33 \\
Korea & 0.13 & China & 0.33 \\
Netherlands & 0.14 & Brazil & 0.41 \\
Brazil & 0.14 & Philippines & 0.42 \\
Venezuela & 0.14 & Chile & 0.42 \\
United Kingdom & 0.16 & United Kingdom & 0.43 \\
Hong Kong & 0.16 & Hong Kong & 0.44 \\
Indonesia & 0.17 & France & 0.44 \\
Mexico & 0.17 & Venezuela & 0.45 \\
Canada & 0.17 & Indonesia & 0.45 \\
France & 0.17 & Korea & 0.45 \\
India & 0.18 & India & 0.46 \\
Italy & 0.19 & Italy & 0.46 \\
Philippines & 0.19 & Canada & 0.47 \\
Japan & 0.20 & Germany & 0.49 \\
Germany & 0.20 & Thailand & 0.56 \\
Chile & 0.21 & Japan & 0.62 \\
Thailand & 0.22 & Mexico & 0.65 \\
Taiwan & 0.24 & Taiwan & 0.67 \\
\hline
\end{tabular}

Note: This table shows, for each of the top 20 trading partners of the United States, what share of relationship counts (left panel) and what share of trade value (right panel) are in relationships that have appeared for four or more consecutive years. 
Table 3: Rank Correlations

\begin{tabular}{lcc}
\hline Sector & Share of Trade in Old Relationships & Share of Old Relationships \\
\hline Textiles & 0.68 & 0.18 \\
Footwear/Headgear & 0.42 & 0.26 \\
Machinery/Electronics & 0.66 & 0.26 \\
\hline
\end{tabular}

Note: The first column presents rank correlations between a country's share of trade in older relationships and a country's share of trade in older relationships (3 or more years) in a particular sector, where textiles are HS2 50-63, Machinery and Electrical Goods are HS2 84-85, and Footwear/Headgear are HS2 64-67. The second column does the same for the share of old relationships. The positive correlations imply countries with high trade in old relationships, also have high trade in old relationships across different sectors. 
Table 4: Traded Value within a Relationship

Dependent Variable: Value $_{m x, t}$

\begin{tabular}{|c|c|c|c|c|c|c|c|c|}
\hline & $(1)$ & $\overline{(2)}$ & $\overline{(3)}$ & $(4)$ & $(5)$ & $(6)$ & $\overline{(7)}$ & (8) \\
\hline Age $=1$ & $\begin{array}{l}0.657 \\
(0.018)\end{array}$ & $\begin{array}{l}0.666 \\
(0.020)\end{array}$ & $\begin{array}{l}0.664 \\
(0.033)\end{array}$ & $\begin{array}{l}0.307 \\
(0.024)\end{array}$ & $\begin{array}{l}0.081 \\
(0.013)\end{array}$ & $\begin{array}{l}0.114 \\
(0.014)\end{array}$ & $\begin{array}{l}0.142 \\
(0.036)\end{array}$ & $\begin{array}{l}0.036 \\
(0.023)\end{array}$ \\
\hline Age $=2$ & $\begin{array}{l}0.740 \\
(0.021)\end{array}$ & $\begin{array}{l}0.841 \\
(0.025)\end{array}$ & $\begin{array}{l}0.819 \\
(0.034)\end{array}$ & $\begin{array}{l}0.479 \\
(0.031)\end{array}$ & $\begin{array}{l}0.104 \\
(0.017)\end{array}$ & $\begin{array}{l}0.218 \\
(0.022)\end{array}$ & $\begin{array}{l}0.226 \\
(0.039)\end{array}$ & $\begin{array}{l}0.146 \\
(0.023)\end{array}$ \\
\hline Age $=3$ & $\begin{array}{l}0.622 \\
(0.024)\end{array}$ & $\begin{array}{l}0.887 \\
(0.025)\end{array}$ & $\begin{array}{l}0.954 \\
(0.041)\end{array}$ & $\begin{array}{l}0.487 \\
(0.036)\end{array}$ & $\begin{array}{l}-0.052 \\
(0.026)\end{array}$ & $\begin{array}{l}0.190 \\
(0.022)\end{array}$ & $\begin{array}{l}0.303 \\
(0.051)\end{array}$ & $\begin{array}{l}0.127 \\
(0.025)\end{array}$ \\
\hline$A g e=4$ & $\begin{array}{l}0.493 \\
(0.021)\end{array}$ & $\begin{array}{l}0.861 \\
(0.027)\end{array}$ & $\begin{array}{l}1.031 \\
(0.043)\end{array}$ & $\begin{array}{l}0.503 \\
(0.040)\end{array}$ & $\begin{array}{l}-0.195 \\
(0.023)\end{array}$ & $\begin{array}{l}0.156 \\
(0.028)\end{array}$ & $\begin{array}{l}0.328 \\
(0.049)\end{array}$ & $\begin{array}{c}0.121 \\
(0.037)\end{array}$ \\
\hline$A g e=5$ & $\begin{array}{l}-0.106 \\
(0.023)\end{array}$ & $\begin{array}{c}0.661 \\
(0.027)\end{array}$ & $\begin{array}{l}1.060 \\
(0.037)\end{array}$ & $\begin{array}{l}0.502 \\
(0.036)\end{array}$ & $\begin{array}{l}-0.840 \\
(0.030)\end{array}$ & $\begin{array}{l}-0.069 \\
(0.025)\end{array}$ & $\begin{array}{l}0.340 \\
(0.047)\end{array}$ & $\begin{array}{l}0.109 \\
(0.037)\end{array}$ \\
\hline Age $=6$ & & $\begin{array}{l}0.486 \\
(0.027)\end{array}$ & $\begin{array}{l}0.984 \\
(0.026)\end{array}$ & $\begin{array}{l}0.641 \\
(0.031)\end{array}$ & & $\begin{array}{l}-0.263 \\
(0.033)\end{array}$ & $\begin{array}{l}0.236 \\
(0.035)\end{array}$ & $\begin{array}{l}0.241 \\
(0.032)\end{array}$ \\
\hline$A g e=7$ & & $\begin{array}{l}-0.115 \\
(0.0311)\end{array}$ & $\begin{array}{l}0.894 \\
(0.025)\end{array}$ & $\begin{array}{l}0.693 \\
(0.034)\end{array}$ & & $\begin{array}{l}-0.912 \\
(0.039)\end{array}$ & $\begin{array}{l}0.123 \\
(0.033)\end{array}$ & $\begin{array}{l}0.278 \\
(0.028)\end{array}$ \\
\hline$A g e=8$ & & & $\begin{array}{l}0.611 \\
(0.025)\end{array}$ & $\begin{array}{l}0.721 \\
(0.032)\end{array}$ & & & $\begin{array}{l}-0.145 \\
(0.031)\end{array}$ & $\begin{array}{l}0.306 \\
(0.029)\end{array}$ \\
\hline Age $=9$ & & & $\begin{array}{l}0.392 \\
(0.029)\end{array}$ & $\begin{array}{l}0.638 \\
(0.035)\end{array}$ & & & $\begin{array}{l}-0.417 \\
(0.045)\end{array}$ & $\begin{array}{l}0.203 \\
(0.037)\end{array}$ \\
\hline Age $=10$ & & & $\begin{array}{l}-0.118 \\
(0.039)\end{array}$ & $\begin{array}{l}0.536 \\
(0.035)\end{array}$ & & & $\begin{array}{l}-0.994 \\
(0.060)\end{array}$ & $\begin{array}{l}0.088 \\
(0.036)\end{array}$ \\
\hline Age $=11$ & & & & $\begin{array}{l}0.079 \\
(0.053)\end{array}$ & & & & $\begin{array}{l}-0.373 \\
(0.061)\end{array}$ \\
\hline Age $=12$ & & & & $\begin{array}{l}0.162 \\
(0.045)\end{array}$ & & & & $\begin{array}{l}-0.296 \\
(0.055)\end{array}$ \\
\hline Age $=13$ & & & & $\begin{array}{l}0.053 \\
(0.049)\end{array}$ & & & & $\begin{array}{l}-0.405 \\
(0.056)\end{array}$ \\
\hline Constant & $\begin{array}{l}11.117 \\
(0.018)\end{array}$ & $\begin{array}{l}11.319 \\
(0.023)\end{array}$ & $\begin{array}{l}11.495 \\
(0.026)\end{array}$ & $\begin{array}{l}12.317 \\
(0.028)\end{array}$ & $\begin{array}{l}11.873 \\
(0.019)\end{array}$ & $\begin{array}{l}12.151 \\
(0.020)\end{array}$ & $\begin{array}{l}12.239 \\
(0.032)\end{array}$ & $\begin{array}{l}12.847 \\
(0.028)\end{array}$ \\
\hline $\mathrm{N}$ & 443000 & 201000 & 77000 & 65000 & 152000 & 75000 & 34000 & 47000 \\
\hline R-squared & 0.74 & 0.73 & 0.71 & 0.72 & 0.76 & 0.75 & 0.71 & 0.72 \\
\hline
\end{tabular}

Note: This table presents results on the growth of trade values within relationships. The value of trade is regressed on age fixed effects, controlling for relationship fixed effects; see Equation 1. The omitted category is trade in the first year $(A g e=0)$. Data is from relationships formed in the years from 1998 to 2006. Columns (1) through (4) show results for all relationships, while columns (5) through (8) show results for relationships that started trading between January and March of their first year. Trade values are available through 2011. Standard errors are in parentheses. 
Table 5: Determinants of Importer-Exporter Relationship Length, 2011

Dependent Variable: $A g e_{m x c}$

\begin{tabular}{|c|c|c|c|c|c|c|}
\hline & (1) & $(2)$ & (3) & (4) & $(5)$ & (6) \\
\hline \multicolumn{7}{|c|}{ Importer Controls } \\
\hline \multirow{2}{*}{ Size $_{m}$} & -0.027 & -0.027 & -0.027 & -0.027 & -0.026 & -0.026 \\
\hline & $(0.026)$ & $(0.026)$ & $(0.026)$ & $(0.026)$ & $(0.025)$ & $(0.025)$ \\
\hline \multirow[t]{2}{*}{$A g e_{m}$} & 0.044 & 0.044 & 0.044 & 0.044 & 0.045 & 0.044 \\
\hline & $(0.005)$ & $(0.005)$ & $(0.004)$ & $(0.004)$ & $(0.004)$ & $(0.004)$ \\
\hline \multirow[t]{2}{*}{ RelCount $_{m}$} & 0.064 & 0.064 & 0.062 & 0.062 & 0.061 & 0.06 \\
\hline & $(0.035)$ & $(0.035)$ & $(0.034)$ & $(0.034)$ & $(0.034)$ & $(0.033)$ \\
\hline \multirow{2}{*}{ NoProducts $_{m}$} & 0.294 & 0.296 & 0.297 & 0.297 & 0.298 & 0.298 \\
\hline & $(0.053)$ & $(0.053)$ & $(0.053)$ & $(0.053)$ & $(0.052)$ & $(0.052)$ \\
\hline \multicolumn{7}{|c|}{ Exporter Controls } \\
\hline \multirow[t]{2}{*}{ Size $_{x}$} & 0.232 & 0.232 & 0.233 & 0.233 & 0.234 & 0.234 \\
\hline & $(0.013)$ & $(0.013)$ & $(0.013)$ & $(0.013)$ & $(0.013)$ & $(0.013)$ \\
\hline \multirow[t]{2}{*}{ RelCount $_{x}$} & -0.375 & -0.376 & -0.378 & -0.379 & -0.383 & -0.384 \\
\hline & $(0.016)$ & $(0.016)$ & $(0.016)$ & $(0.016)$ & $(0.016)$ & $(0.015)$ \\
\hline \multicolumn{7}{|c|}{ Country Controls } \\
\hline \multirow[t]{2}{*}{ RuleOf Law } & & 0.122 & 0.124 & 0.119 & 0.126 & \\
\hline & & $(0.012)$ & $(0.013)$ & $(0.016)$ & $(0.012)$ & \\
\hline \multirow[t]{2}{*}{$P C-G D P_{c}$} & 0.164 & 0.073 & -0.006 & & 0.031 & \\
\hline & $(0.020)$ & $(0.019)$ & $(0.014)$ & & $(0.011)$ & \\
\hline \multirow[t]{2}{*}{$O E C D_{c}$} & & & 0.238 & 0.228 & 0.142 & \\
\hline & & & $(0.021)$ & $(0.023)$ & $(0.015)$ & \\
\hline \multirow[t]{2}{*}{$R T A_{c}$} & & & & 0.021 & 0.009 & \\
\hline & & & & $(0.017)$ & $(0.038)$ & \\
\hline \multirow[t]{2}{*}{ Distance $_{c}$} & & & & & -0.018 & \\
\hline & & & & & $(0.032)$ & \\
\hline \multirow[t]{2}{*}{ Constant } & -2.585 & -1.766 & -1.132 & -1.19 & -2.595 & -1.304 \\
\hline & $(0.297)$ & $(0.287)$ & $(0.255)$ & $(0.209)$ & $(0.337)$ & $(0.218)$ \\
\hline $\mathrm{N}$ & $1,075,100$ & $1,075,100$ & $1,075,100$ & $1,075,100$ & $1,075,100$ & $1,075,100$ \\
\hline HS2 FE & yes & yes & yes & yes & yes & yes \\
\hline Country FE & no & no & no & no & no & yes \\
\hline $\mathrm{R}^{2}$ & 0.11 & 0.11 & 0.12 & 0.12 & 0.12 & 0.12 \\
\hline
\end{tabular}

Note: This table presents results on the role of firm and country institutions on the age of relationships. Each regression includes source country and primary-HS2 product effects. Standard errors clustered by source country are in parentheses. The dependent variable is the age of a relationship in 2011, defined as the number of consecutive years a relationship has been found in the data, and is capped at 11. 
Table 6: Parameters and the Value of Relationships

\begin{tabular}{l|ccc|ccc}
\hline \hline & $(1)$ & $(2)$ & $(3)$ & $(4)$ & $(5)$ & $(6)$ \\
\hline Country & $\lambda$ & $\hat{\theta}$ & $\delta$ & $\begin{array}{c}\text { Value of a } \\
\text { New Relationship }\end{array}$ & $\begin{array}{c}\text { Value of an } \\
\text { Old Relationship }\end{array}$ & Ratio \\
\hline Canada & 0.31 & 0.13 & 0.27 & 3.5 & 45.2 & 13 \\
China & 0.31 & 0.33 & 0.37 & 6.6 & 33.5 & 5.1 \\
Germany & 0.41 & 0.08 & 0.17 & 4.8 & 71.3 & 15 \\
France & 0.35 & 0.01 & 0.05 & 3.1 & 242.6 & 79 \\
India & 0.39 & 0.13 & 0.2 & 5.9 & 60.9 & 10.3 \\
Japan & 0.36 & 0.10 & 0.17 & 5.4 & 73 & 13.5 \\
Korea & 0.35 & 0.10 & 0.23 & 3.8 & 53.8 & 14.2 \\
Mexico & 0.34 & 0.05 & 0.05 & 10.6 & 238 & 22.5 \\
Taiwan & 0.36 & 0.22 & 0.19 & 10.9 & 64.6 & 5.9 \\
United Kingdom & 0.36 & 0.04 & 0.19 & 2 & 65.3 & 33.1 \\
\hline \hline
\end{tabular}

Note: This table presents parameter estimates for the 10 jurisdictions from which the United States imported the most in 2011. In columns (4) and (5), it also presents the expected sum of profits from a new and an old relationship, respectively. Column (6) reports the ratio of the expected sum of profits from an old relationship over those from a new relationship.

Table 7: Alternative Models

\begin{tabular}{lccccccc}
\hline \hline Model & \multirow{2}{*}{ Error } & \multicolumn{2}{c}{$\lambda$} & \multicolumn{2}{c}{$\hat{\theta}$} & \multicolumn{2}{c}{$\delta$} \\
& & $\min$ & $\max$ & $\min$ & $\max$ & $\min$ & $\max$ \\
\hline Full & 1 & 0.31 & 0.41 & 0.01 & 0.33 & 0.05 & 0.37 \\
$\delta$ Only & 6.78 & \multicolumn{2}{c}{1} & \multicolumn{2}{c}{1} & 0.35 & 0.59 \\
Fixed $\hat{\theta}$ & 1.25 & 0.31 & 0.44 & 0.11 & 0.1 & 0.33 \\
Fixed $\lambda$ & 1.07 & \multicolumn{2}{c}{0.36} & 0.02 & 0.28 & 0.05 & 0.35 \\
\hline
\end{tabular}

Note: This figure presents results from alternative models. Error is the sum of squared errors, as defined in Equation (29), normalized to one for the full model. 
Table 8: Relationship Margins during the Trade Collapse

Counts Relative to 2007

\begin{tabular}{lcccc}
\hline \hline Year & 2007 & 2008 & 2009 & 2010 \\
Relationship Counts & 1 & 0.97 & 0.90 & 0.98 \\
New Relationship Counts & 1 & 0.93 & 0.85 & 0.96 \\
Continuing-Relationship Counts & 1 & 1.03 & 0.97 & 0.99 \\
Ending-Relationship Counts & 1 & 1.02 & 1.02 & 0.88 \\
\hline
\end{tabular}

Note: This table describes relationship formation, dissolution and continuation in the years around the 2008-09 Great Trade Collapse. Each category is normalized by the baseline year 2007. A new relationship is one not observed in any prior year. A continuing relationship is one that is found in both the current year and the previous year. An ending relationship is one that is found in the current year, but not the next year. 
Table 9: Relationship Value and Survival during the 2008/2009 Crisis Dependent Variable: Survival Probabilityckt

\begin{tabular}{|c|c|c|c|c|c|c|c|}
\hline & (1) & $(2)$ & $(3)$ & (4) & $(5)$ & (6) & $(7)$ \\
\hline \multirow[t]{2}{*}{$A g e=2$} & 0.198 & 0.199 & & & 0.188 & & \\
\hline & $(0.007)$ & $(0.007)$ & & & $(0.007)$ & & \\
\hline \multirow[t]{2}{*}{$A g e=3$} & 0.301 & 0.303 & & & 0.289 & & \\
\hline & $(0.007)$ & $(0.007)$ & & & $(0.008)$ & & \\
\hline \multirow[t]{2}{*}{$A g e=4$} & 0.355 & 0.359 & & & 0.344 & & \\
\hline & $(0.007)$ & $(0.007)$ & & & $(0.008)$ & & \\
\hline \multirow[t]{2}{*}{$A g e=5$} & 0.394 & 0.399 & & & 0.383 & & \\
\hline & $(0.007)$ & $(0.007)$ & & & $(0.008)$ & & \\
\hline \multirow[t]{2}{*}{$A g e=6$} & 0.415 & 0.421 & & & 0.410 & & \\
\hline & $(0.007)$ & $(0.008)$ & & & $(0.008)$ & & \\
\hline \multirow[t]{2}{*}{$A g e=7$} & 0.430 & 0.436 & & & 0.420 & & \\
\hline & $(0.007)$ & $(0.008)$ & & & $(0.008)$ & & \\
\hline \multirow[t]{2}{*}{ Crisis $_{t}$} & -0.023 & & & & & & \\
\hline & $(0.005)$ & & & & & & \\
\hline \multirow[t]{2}{*}{$V_{c k}$} & & -0.007 & & & -0.008 & & \\
\hline & & $(0.003)$ & & & $(0.003)$ & & \\
\hline \multirow[t]{2}{*}{ Crisis $_{t} \times V_{c k}$} & & 0.010 & 0.011 & 0.009 & 0.011 & 0.012 & 0.010 \\
\hline & & $(0.004)$ & $(0.004)$ & $(0.004)$ & $(0.004)$ & $(0.004)$ & $(0.004)$ \\
\hline \multirow[t]{2}{*}{ Crisis $_{t} \times$ Age } & & & & 0.002 & & & 0.003 \\
\hline & & & & $(0.003)$ & & & $(0.0028)$ \\
\hline \multirow[t]{2}{*}{ Average Trade $e_{c k t}$} & & & & & 0.012 & 0.015 & 0.015 \\
\hline & & & & & $(0.002)$ & $(0.002)$ & $(0.002)$ \\
\hline \multirow[t]{2}{*}{ Constant } & 0.269 & 0.272 & 0.568 & 0.568 & 0.127 & 0.371 & 0.370 \\
\hline & $(0.005)$ & $(0.007)$ & $(0.0050)$ & $(0.005)$ & $(0.026)$ & $(0.030)$ & $(0.030)$ \\
\hline Country FE & yes & yes & no & no & yes & no & no \\
\hline Country $\times$ Age FE & no & no & yes & yes & no & yes & yes \\
\hline Time FE & no & yes & yes & yes & yes & yes & yes \\
\hline Observations & 4300 & 4300 & 4300 & 4300 & 4300 & 4300 & 4300 \\
\hline R-squared & 0.59 & 0.59 & 0.65 & 0.65 & 0.60 & 0.66 & 0.66 \\
\hline
\end{tabular}

Note: This table presents results on how our model-implied value of a relationship is correlated with relationship survival during the $2008 / 2009$ crisis. An observation is the survival probability of a relationship in country $c$ of age $k$ at time $t$. $V_{c k}$ is the value of a relationship in country $c$ of age $k$ based on the calibrated model. Crisis $_{t}$ is a dummy that takes a value of one in the year 2008, capturing the survival probability from 2008 to 2009. Standard errors clustered by source country are in parentheses. 
Table 10: Quantification of Relationship Values

\begin{tabular}{lcc}
\hline \hline Name & Exp 1: Reset memory & Exp 2: Destroy relationships \\
\hline Canada & 17.9 & 33.3 \\
China & 12.9 & 31.6 \\
France & 91.7 & 110.4 \\
Germany & 28.9 & 50.9 \\
India & 28.7 & 51.5 \\
Japan & 36.9 & 58.8 \\
Korea & 21.2 & 38.8 \\
Mexico & 189.6 & 222.8 \\
Taiwan & 38.4 & 69.6 \\
United Kingdom & 16.0 & 30.8 \\
\hline \hline
\end{tabular}

Note: This table reports results from two counterfactual experiments that quantify the value of relationships. Numbers represent the cumulative consumption loss that the economy suffers from the beginning of the experiment until convergence back to steady state. 


\section{Solving the General Equilibrium Model}

\section{C.1 Equilibrium Conditions}

In the two-country model, there are six equilibrium conditions (three for each country). To keep the equations tractable, it is useful to introduce some notation. We shorten the equation for domestic profits to:

$$
\mathrm{E}\left[\pi_{t, k}^{i i}\right]=\frac{1}{\sigma}\left(p_{t}^{i i}\right)^{1-\sigma} A_{t}^{i}=\frac{r_{t}^{i i}}{\sigma} A_{t}^{i}
$$

with $r_{t}^{i i}=\left(p_{t}^{i i}\right)^{1-\sigma}=\left(\frac{\sigma}{\sigma-1} c^{i} w_{t}^{i}\right)^{1-\sigma}$. For the foreign country we have $r_{t}^{j j}=$ $\left(p_{t}^{j j}\right)^{1-\sigma}=\left(\frac{\sigma}{\sigma-1} c^{j} w_{t}^{j}\right)^{1-\sigma}$. We shorten expected profits from exporting in Equation (10) to:

$$
\mathrm{E}\left[\pi_{t, k}^{i j}\right]=\frac{\tilde{\theta}_{k}^{i}}{\sigma}\left(p_{t, k}^{i j}\right)^{1-\sigma} A_{t}^{j}=\frac{r_{t, k}^{i j}}{\sigma} A_{t}^{j},
$$

with $r_{t, k}^{i j}=\tilde{\theta}_{k}^{i}\left(p_{t, k}^{i j}\right)^{1-\sigma}=\tilde{\theta}_{k}^{i}\left(\frac{\tau}{\tilde{\theta}_{k}^{i}} p_{t}^{i i}\right)^{1-\sigma}$. For the foreign country, we have $r_{t, k}^{j i}=$ $\tilde{\theta}_{k}^{j}\left(p_{t, k}^{j i}\right)^{1-\sigma}=\tilde{\theta}_{k}^{j}\left(\frac{\tau}{\tilde{\theta}_{k}^{j}} p_{t}^{j j}\right)^{1-\sigma}$.

Free entry First, free entry must hold in both countries such that the expected sum of future profits of an entrant at time $t$ is equal to the fixed cost of entering production $\sqrt{34}$ Normalizing the home wage to $w_{t}^{i}=1$, we get:

$$
\begin{aligned}
f_{E} & =\sum_{s=0}^{K} \operatorname{alive}_{s}^{i j}\left(\pi_{t+s, s}^{i i}+\pi_{t+s, s}^{i j}\right) \\
w_{t}^{j} f_{E} & =\sum_{s=0}^{K} \operatorname{alive}_{s}^{j i}\left(\pi_{t+s, s}^{j j}+\pi_{t+s, s}^{j i}\right)
\end{aligned}
$$

where alive $_{k}$ is the probability that a relationship survives $k$ years, as previously 35 Now, replacing profits by the expressions in equations and (C.1) and (19), we can

\footnotetext{
${ }^{34} \mathrm{As}$ in Krugman (1980), we do not assume any fixed cost of exporting, so that any firm that enters also exports. In addition, we assume that if a trade relationship gets resolved, the firm also ceases to sell domestically. The latter assumption is mainly for tractability and could be relaxed.

${ }^{35}$ For data simplicity, we assume this probability is not time-varying, but it would be straightforward to allow.
} 
rewrite to:

$$
\begin{aligned}
\sigma f_{E} & =\sum_{s=0}^{K} \operatorname{alive}_{s}^{i j}\left(r_{t+s}^{i i} A_{t+s}^{i}+r_{t+s, s}^{i j} A_{t+s}^{j}\right) \\
w_{t}^{j} \sigma f_{E} & =\sum_{s=0}^{K} \operatorname{alive}_{s}^{j i}\left(r_{t+s}^{j j} A_{t+s}^{j}+r_{t+s, s}^{j i} A_{t+s}^{j}\right)
\end{aligned}
$$

Isolating the first term of the sum, combining the two equations, then solving for the home and foreign demand delivers:

$$
\begin{aligned}
& A_{t}^{i}=\frac{r_{t}^{i i}\left(\sigma f_{E}-\Pi_{t, 1+}^{i}\right)-r_{t, 0}^{i j}\left(w_{t}^{j} \sigma f_{E}-\Pi_{t, 1+}^{j}\right)}{r_{t}^{i i} r_{t}^{j j}-r_{t, 0}^{i j} r_{t, 0}^{j i}} \\
& A_{t}^{j}=\frac{r_{t}^{j j}\left(w_{t}^{j} \sigma f_{E}-\Pi_{t, 1+}^{j}\right)-r_{t, 0}^{j i}\left(\sigma f_{E}-\Pi_{t, 1+}^{i}\right)}{r_{t}^{i i} r_{t}^{j j}-r_{t, 0}^{i j} r_{t, 0}^{j i}}
\end{aligned}
$$

with $\Pi_{t, 1+}^{i}=\sum_{s=1}^{K} \operatorname{alive}_{s}^{i j}\left(r_{t}^{i i} A_{t+s}^{i}+r_{t+s, s}^{i j} A_{t+s}^{j}\right)$ and $\Pi_{1+}^{j}=\sum_{s=1}^{K} \operatorname{alive}_{s}^{j i}\left(r_{t}^{j j} A_{t+s}^{j}+r_{t+s, s}^{j i} A_{t+s}^{i}\right)$ the sums of expected profits from period 1 onwards.

Labor market clearing Second, labor markets in both countries need to clear. Call the mass of firms in country $i$ at time $t$ of age $k N_{t, k}^{i}$, and total labor in country $i L^{i}$. Then,

$$
\begin{gathered}
L^{i}=N_{t, 0}^{i} f_{E}+\sum_{s=0}^{K} N_{t, s}^{i} c^{i}\left(\left(p_{t}^{i i}\right)^{-\sigma} A_{t}^{i}+\tau\left(p_{t, s}^{i j}\right)^{-\sigma} A_{t}^{j}\right) \\
L^{j}=N_{t, 0}^{j} f_{E}+\sum_{s=0}^{K} N_{t, s}^{j} c^{j}\left(\left(p_{t}^{j j}\right)^{-\sigma} A_{t}^{j}+\tau\left(p_{t, s}^{j i}\right)^{-\sigma} A_{t}^{i}\right)
\end{gathered}
$$

Solving for entry in period $t$ by isolating the firm term of the sum delivers:

$$
\begin{aligned}
N_{t, 0}^{i} & =\frac{L^{i}-L_{P, t, 1+}^{i}}{f_{E}+c^{i}\left(\left(p_{t}^{i i}\right)^{-\sigma} A_{t}^{i}+\tau\left(p_{t, 0}^{i j}\right)^{-\sigma} A_{t}^{j}\right)}, \\
N_{t, 0}^{j}= & \frac{L^{j}-L_{P, t, 1+}^{j}}{f_{E}+c^{j}\left(\left(p_{t}^{j j}\right)^{-\sigma} A_{t}^{j}+\tau\left(p_{t, 0}^{j i}\right)^{-\sigma} A_{t}^{i}\right)},
\end{aligned}
$$

with $L_{P, t, 1+}^{i}=\sum_{s=1}^{K} N_{t, s}^{i} c^{i}\left(\left(p_{t}^{i i}\right)^{-\sigma} A_{t}^{i}+\tau\left(p_{t, s}^{i j}\right)^{-\sigma} A_{t}^{j}\right)$ and $L_{P, t, 1+}^{j}=\sum_{s=1}^{K} N_{t, s}^{j} c^{j}\left(\left(p_{t}^{j j}\right)^{-\sigma} A_{t}^{j}+\tau\left(p_{t, s}^{j i}\right)^{-\sigma} A_{t}^{i}\right)$ the production labor used by all 
firms that are not new in countries $i$ and $j$, respectively.

Balanced trade Finally, balanced trade requires that income equals total expenditure (domestic consumption plus imports) at time $t$.

$$
\begin{aligned}
L^{i} & =A_{t}^{i} \sum_{s=0}^{K}\left(N_{t, s}^{i} r_{t}^{i i}+N_{t, s}^{j} r_{t, s}^{j i}\right) \\
w_{t}^{j} L^{j} & =A_{t}^{j} \sum_{s=0}^{K}\left(N_{t, s}^{j} r_{t}^{j j}+N_{t, s}^{i} r_{t, s}^{i j}\right)
\end{aligned}
$$

\section{C.2 Solving For the Steady State}

We solve the model numerically and then look at shocks to the steady state. In steady state, $A^{i}, A^{j}, w^{j}, r^{i i}$, and $r_{t, s}^{i j}=r_{s}^{i j}$ are constant, so the free entry condition simplifies to:

$$
\begin{aligned}
\sigma f_{E} & =\sum_{s=0}^{K} \operatorname{alive}_{s}^{i j}\left(r^{i i} A^{i}+r_{s}^{i j} A^{j}\right) \\
w^{j} \sigma f_{E} & =\sum_{s=0}^{K} \operatorname{alive}_{s}^{j i}\left(r^{j j} A^{j}+r_{s}^{j i} A^{i}\right)
\end{aligned}
$$

And the demand solutions become:

$$
\begin{aligned}
A^{i} & =\frac{\sigma f_{E}-A^{j} \sum_{s=0}^{\infty} \operatorname{alive}_{s}^{i j} r_{s}^{i j}}{r^{i i} M_{S S}^{i}}, \\
A^{j} & =\frac{w^{j} \sigma f_{E}-A^{i} \sum_{s=0}^{\infty} \operatorname{alive}_{s}^{j i} r_{s}^{j i}}{r^{j j} M_{S S}^{j}},
\end{aligned}
$$

with $M_{S S}^{i}$ and $M_{S S}^{j}$ the steady-state mass of firms in the home and destination country, respectively. We call $M^{i}$ the steady-state mass of firms in country $i$. Combining the two equations and solving for the actual demand levels yields:

$$
\begin{aligned}
A^{i} & =\frac{\sigma f_{E}\left(r^{j j} M^{j}-w^{j} \sum_{s=0}^{K} \operatorname{alive}_{s}^{i j} r_{s}^{i j}\right)}{r^{i i} M^{i} r^{j j} M^{j}-\sum_{s=0}^{K} \operatorname{alive}_{s}^{i j} r_{s}^{i j} \sum_{s=0}^{K} \operatorname{alive}_{s}^{j i} r_{s}^{j i}} \\
A^{j} & =\frac{\sigma f_{E}\left(w^{j} r^{i i} M^{i}-\sum_{s=0}^{K} \operatorname{alive}_{s}^{j i} r_{s}^{j i}\right)}{r^{i i} M^{i} r^{j j} M^{j}-\sum_{s=0}^{K} \operatorname{alive}_{s}^{i j} r_{s}^{i j} \sum_{s=0}^{K} \operatorname{alive}_{s}^{j i} r_{s}^{j i}}
\end{aligned}
$$


Recalling from Section 4.3 that ageshare $_{k}$ is the share of relationships of age $k$ out of all relationships, labor clearing simplifies to:

$$
\begin{aligned}
L^{i} & =M^{i}\left(\operatorname{ageshare}_{0}^{i} f_{E}+\sum_{s=0}^{K} \operatorname{ageshare}_{s}^{i} c^{i}\left(\left(p^{i i}\right)^{-\sigma} A^{i}+\tau\left(p_{s}^{i j}\right)^{-\sigma} A^{j}\right)\right) \\
L^{j} & =M^{j}\left(\operatorname{ageshare}_{0}^{j} f_{E}+\sum_{s=0}^{K} \operatorname{ageshare}_{s}^{j} c^{j}\left(\left(p^{j j}\right)^{-\sigma} A^{j}+\tau\left(p_{s}^{j i}\right)^{-\sigma} A^{i}\right)\right)
\end{aligned}
$$

Solving for the mass of firms delivers:

$$
\begin{aligned}
M^{i} & =\frac{L^{i}}{\operatorname{ageshare}_{0}^{i} f_{E}+\sum_{s=0}^{K} \operatorname{ageshare~}_{s}^{i} c^{i}\left(\left(p^{i i}\right)^{-\sigma} A^{i}+\tau\left(p_{s}^{i j}\right)^{-\sigma} A^{j}\right)} \\
M^{j} & =\frac{L^{j}}{\operatorname{ageshare~}_{0}^{j} f_{E}+\sum_{s=0}^{K} \operatorname{ageshare~}_{s}^{j} c^{j}\left(\left(p^{j j}\right)^{-\sigma} A^{j}+\tau\left(p_{s}^{j i}\right)^{-\sigma} A^{i}\right)}
\end{aligned}
$$

And the balanced budget conditions reduce to:

$$
\begin{aligned}
L^{i} & =A^{i}\left(r^{i i} M^{i}+M^{j} \sum_{s=0}^{K} \operatorname{ageshare~}_{s}^{j} r_{s}^{j i}\right) \\
L^{j} & =A^{j}\left(r^{j j} M^{j}+M^{i} \sum_{s=0}^{K} \operatorname{ageshare~}_{s}^{i} r_{s}^{i j}\right)
\end{aligned}
$$

We can combine the previous expressions to obtain two balanced budget conditions with one unknown $w^{j}$. Either would be sufficient to solve the model. However, for the numerical solution, it turns out to be helpful to use both equations in the minimization problem.

\section{Relaxing Cash-In-Advance Payments}

In this appendix, we demonstrate how equations in the model can be relaxed so that cash-in-advance is not the only way to allow payment. To do so, define $\alpha$ as the percent of the bill to be paid in advance. 


\section{D.1 Firm Optimization}

Expected profits Expected exporter profits when buying from a supplier that an importer has traded with for $k$ periods and an option to pay later are

$$
\mathrm{E}\left[\pi_{t, k}^{i, j}\right]=\tilde{\theta}_{k}^{i}\left[p_{t, k}^{i j} q_{t, k}^{i j}-(1-\alpha) T_{k}^{i j}\right]-\alpha T_{k}^{i j}-\tau w_{t}^{i} c^{i} q_{t, k}^{i j}
$$

where now $T_{k}^{i j}$ is the agreed payment from the importer to the exporter. The buyer can assemble the final goods and sell them for revenue $p_{t, k}^{i j} q_{t, k}^{i j}$ if the intermediate inputs are usable. In that case, the buyer will also pay the remaining outstanding bill of $(1-\alpha) T_{k}^{i j}$. In any case, the importer will incur the prepayment to the importer, $\alpha T_{k}$, and the prepayment to its own workers, $w^{i} c_{2}^{i} q$.

We assume that there are no financing costs and that suppliers do not discount the future, so advance payments are not valued more than post-delivery payments $\sqrt[36]{6}$ The participation constraint for the supplier in $i$ to produce according to the specification of its buyer is given by $\alpha T_{k}+(1-\alpha) T_{k} \geq c_{1}^{i} q_{t, k}^{i j}{ }^{37}$ As the buyer has all bargaining power, this constraint binds in equilibrium, so that $T_{k}=T=c_{1}^{i} q_{t, k}^{i j}$. Plugging this back into expected profits delivers

$$
\mathrm{E}\left[\pi_{k}\right]=\tilde{\theta}_{k}\left[p_{t, k}^{i j} q_{t, k}^{i j}-(1-\alpha) c_{1}^{i} q_{t, k}^{i j}\right]-\alpha c_{1}^{i} q_{t, k}^{i j}-\tau w_{t}^{i} c_{2}^{i} q_{t, k}^{i j}
$$

CES Demand Continue to assume that demand for the final good has the standard CES form: $q_{t, k}^{i j}=A_{t}^{j}\left(p_{t, k}^{i j}\right)^{-\sigma}=P_{t}^{\sigma} Q_{t}\left(p_{t, k}^{i j}\right)^{-\sigma}$, with elasticity of substitution $\sigma>1$. Expected importer profits in a relationship that has lasted $k$ periods are given by Equation (D.1), where revenue at any time $t$ is $p_{t, k}^{i j} q_{t, k}^{i j}$. Profit maximization implies the optimal price:

$$
p_{t, k}^{i j}=\frac{\sigma w_{t}^{i} \tau}{\sigma-1}\left[(1-\alpha) c_{1}^{i}+\frac{\alpha c_{1}^{i}+c_{2}^{i}}{\tilde{\theta}_{k}^{i}}\right] .
$$

This expression is quite intuitive. The importer only pays $(1-\alpha) c_{1}^{i}$ when the delivered inputs are of high quality, so these costs affect the optimal price-setting in the standard way. $\alpha c_{1}^{i}$ and $c_{2}^{i}$ are the costs of prepayment to the exporter

\footnotetext{
${ }^{36}$ It would be easy to relax either of these assumptions, but it would not add any value to the analysis. See Schmidt-Eisenlohr (2013) for a model of payment choices with positive interest rates.

${ }^{37}$ We assume that the buyer always offers a contract that is acceptable to patient and impatient sellers, so the patient-buyer participation constraint is the relevant one. In principle, there could be a separating case where the buyers offer a low total payment, $T_{K}$, and only attracts the impatient suppliers. However, as shown in Schmidt-Eisenlohr (2013), the pooling dominates under very weak conditions.
} 
and the local workers, respectively, that are incurred independently of the success of the transaction. Optimal price setting allocates these costs evenly across all successful transactions, so the lower $\tilde{\theta}_{k}^{i}$ is, the more these costs increase the price demanded from final consumers. Importers do standard markup pricing over the effective costs per unit of output, $(1-\alpha) c_{1}^{i}+\frac{\alpha c_{1}^{i}+c_{2}^{i}}{\tilde{\theta}_{k}}$. This implies that a successful transaction generates revenues of

$$
R_{t, k}^{i j}=p_{t, k}^{i j} q_{t, k}^{i j}=A_{t}^{j}\left(\frac{\sigma \tau w_{t}^{i}}{\sigma-1}\right)^{1-\sigma}\left[(1-\alpha) c_{1}^{i}+\frac{\alpha c_{1}^{i}+c_{2}^{i}}{\tilde{\theta}_{k}^{i}}\right]^{1-\sigma}
$$

As in the main text, we can show the following proposition that matches our empirical finding:

Proposition 2 The amount being traded, $R_{t, k}^{i j}$, within a relationship increases with the relationship's age, $k$.

Proof.

$\frac{\partial}{\partial k} R_{t, k}^{i j}=A_{t}^{j}\left(\frac{\sigma \tau w_{t}^{i}}{\sigma-1}\right)^{1-\sigma}(1-\sigma)\left[(1-\alpha) c_{1}^{i}+\frac{\alpha c_{1}^{i}+c_{2}^{i}}{\tilde{\theta}_{k}^{i}}\right]^{-\sigma}\left(\alpha c_{1}^{i}+c_{2}^{i}\right)(-1)\left(\tilde{\theta}_{k}^{i}\right)^{-2} \frac{\partial}{\partial k} \tilde{\theta}_{k}^{i}>0$

as $\tilde{\theta}_{k}^{i}=\left(\frac{\widehat{\theta}}{\widehat{\theta}+(1-\widehat{\theta}) \lambda^{k}}\right)(1-\lambda)+\lambda$ is increasing in $k$ for $\lambda<1$.

Trade shares by age Although the expression for the count distribution does not change, because exporter revenues now also depend on $\alpha$, the expression for the value distribution is altered.

$$
\text { tradeshare }_{k}=\left(R_{t, k}^{i j} \text { alive }_{k}\right) / \sum_{s=0}^{K}\left(R_{t, s}^{i j} \text { alive }_{s}\right)
$$

Plugging in the expression for revenues (D.3), we obtain

$$
\text { tradeshare }_{k}=\frac{\left[(1-\alpha) c_{1}+\left(\frac{\alpha c_{1}+c_{2}}{\tilde{\theta}_{k}}\right)\right]^{1-\sigma} \text { alive }_{k}}{\sum_{s=0}^{K}\left[(1-\alpha) c_{1}+\left(\frac{\alpha c_{1}+c_{2}}{\tilde{\theta}_{s}}\right)\right]^{1-\sigma} \text { alive }_{s}} .
$$


Value of a relationship Our calculations for the value of a relationship are also altered as a result of revenues depending on two separate costs. Consider the expected profit stream for a supplier in $i$ beginning a wholly new relationship with a firm in $j$.

$$
\begin{aligned}
V_{0}=\mathrm{E}\left[\Pi_{0}\right] & =\sum_{s=0}^{K} \text { alive }_{s} \mathrm{E}\left[\pi_{s}^{i j}\right] \\
& =\frac{1}{\sigma}\left(\tau p^{i i}\right)^{1-\sigma} A^{j} \sum_{s=0}^{K}(1-\delta)^{s}\left(\lambda^{s}(1-\hat{\theta})+\hat{\theta}\right) \tilde{\theta}_{s}^{i}\left[(1-\alpha) c_{1}^{i}+\frac{\alpha c_{1}^{i}+c_{2}^{i}}{\tilde{\theta}_{s}^{i}}\right]^{1-\sigma} .
\end{aligned}
$$

Here, an importer is matched with a random supplier at $s=0$ that delivers a quality input with probability $\hat{\theta}$. The importer then slowly learns the type of the supplier over time. The age-specific version of this measure is

$$
\begin{gathered}
V_{k}=\mathrm{E}\left[\Pi_{k}\right]=\sum_{s=0}^{K-k}\left(\frac{\text { alive }_{k+s}}{\text { alive }_{k}}\right) \mathrm{E}\left[\pi_{k+s}^{i j}\right] \\
=\frac{1}{\sigma}\left(\tau p^{i i}\right)^{1-\sigma} A^{j} \sum_{s=0}^{K-k}(1-\delta)^{s} \frac{\left(\lambda^{k+s}(1-\hat{\theta})+\hat{\theta}\right)}{\left(\lambda^{s}(1-\hat{\theta})+\hat{\theta}\right)} \tilde{\theta}_{k+s}^{i}\left[(1-\alpha) c_{1}^{i}+\frac{\alpha c_{1}^{i}+c_{2}^{i}}{\tilde{\theta}_{k+s}^{i}}\right]^{1-\sigma} .
\end{gathered}
$$

